NASA Technical Memorandum 89865

\title{
Fiber Reinforced Superalloys
}

Donald W. Petrasek and Robert A. Signorelli

Lewis Research Center

Cleveland, Ohio

and

Thomas Caulfield and John K. Tien

Columbia University

New York, New York

(BASA-TH-89865) FIBEE BEINFCECED

SUPERALLCYS (NAS1) $62 \mathrm{p}$ AVAII: NTIS HC

AO4/AF AO1

CSCL 110

$487-22811$

$\begin{array}{ll}\text { G3 } & \text { Daclas } \\ 00724 & 0074224\end{array}$

April 1987 


\section{FIBER REINFORCED SUPERALLOYS}

Donald W. Petrasek and Robert A. Signorelil

National Aeronautics and Space Administration

Lewts Research Center

Cleveland, Ohio 44135

and

Thomas Caulfield and John K. Tien

Columbia University

New York, New York 10027

\section{SUMMARY}

Improved performance of heat engines is largely dependent upon maximum cycle temperatures. Tungsten fiber reinforced superalloys (TFRS) are the first of a family of high temperature composites that offer the potential for significantiy raising hot component operating temperatures and thus leading to improved heat engine performance. This status review of TFRS research emphasizes the promising property data developed to date, the status of TFRS composite airfoil fabrication technology, and the areas requiring more attention to assure their applicability to hot section components of aircraft gas-turbine engines. 
The need for improved materials at elevated temperatures has stimulated research in many areas including efforts to develop fiber reinforced superalloy matrix composites. A number of fibers have been studied for such use including submicron diameter ceramic whiskers, continuous length ceramic filaments, boron filaments, carbon filaments, and refractory metal alloy wires. Attainment of high temperature strength with superalloy matrix composites has been successful using refractory metal alloy wires, but the use of ceramic whiskers, continuous length ceramic filaments, boron filaments or carbon filaments as the reinforcing fiber has been unsuccessful to date.

The theoretical specific strength potential of refractory alloy fiber reinforced superalloys is less than that of ceramic fiber reinforced superalloys. However, the more ductlle metal fiber systems are more tolerant of fiber-matrix reactions and thermal expansion mismatches. Also, the superalloy matrices can protect high strength refractory metal fibers from environmental attack. In laboratory tests, refractory fiber reinforced superalloy composites have demonstrated stress-rupture strengths significantly above those of the strongest superalloys. Tungsten fiber reinforced superalloy composites, in particular, are potentially useful as high temperature $\left(1000\right.$ to $1200{ }^{\circ} \mathrm{C}(1830$ to $2190^{\circ} \mathrm{F}$ ) materials because they have many desirable properties such as good stress-rupture and creep resistance, oxidation resistance, ductility, impact damage resistance, thermal conductivity and microstructural stability. The potential of tungsten fiber reinforced superalloys (TFRS) has been recognized and has stimulated research to develop this material for use in heat engines.

The object of this paper is to review the development of fiber reinforced superalloys. First refractory metal fiber and matrix alloy development will be reviewed. This will be followed by a discussion of fabrication techniques 
for TFRS and property results of importance for their use at high temperatures. Component fabrication and fabrication cost data for a specific TFRS system will then be discussed in the final section.

\section{FIBER DEVELOPMENT}

Refractory metal wires have received a great deal of attention as fiber reinforcement materials for high use temperature composites in spite of their poor oxidation resistance and high density. When used to reinforce a ductile and oxidation resistant matrix, they are protected from oxidation and their specific strength is much higher than that of superalloys at elevated temperatures. The majority of the studies conducted on refractory wire/superalloy composites have used tungsten or molybdenum wire, available as lamp filament or thermocouple wire, as the retnforcement material. These refractory alloys were not designed for use in composites nor for optimum mechanical properties in the temperature range of interest for heat engine application, 1000 to $1200{ }^{\circ} \mathrm{C}$ $\left(1830\right.$ to $\left.2190^{\circ} \mathrm{F}\right)$. Lamp-f 1 lament wire such as $218 \mathrm{CS}$ tungsten was most extensively used in early studies. The stress-rupture properties of 218 CS tungsten wire were superior to those of rod and bulk forms of tungsten and showed promise for use as reinforcement of superalloys. The need for stronger wire was recognized, and high strength tungsten, tantalum, molybdenum, and niobium alloys for which rod and/or sheet-fabrication procedures had already been developed were included in a wire fabrication and test program, (Amra et al., 1970; King, 1972; Petrasek, 1972; and Petrasek and Signore111, 1969). The chemical compositions of these alloy are given in Table I. The above approach precluded development of new alloys specifically designed for strength at the intended composite use temperatures. The stress-rupture and tensile properties determined for the wires developed are summarized in Table II and are compared with commerically avallable wire (218CS, W-l Th0 ${ }_{2}$ and $\mathrm{W}-3 \mathrm{Re}$ ).

Excellent progress was made in providing wires with increased strength compared to the strongest wires which were previously available. The ultimate 
tensile strengths obtalned for the wires at 1093 and $1204{ }^{\circ} \mathrm{C}\left(2000\right.$ and $2200{ }^{\circ} \mathrm{F}$ ) are plotted in Fig. 1. Tungsten alloy wires were fabricated having tensile strengths $2-1 / 2$ times that obtained for $218 \mathrm{CS}$ tungsten wire. The strongest wire fabricated, W-Re-Hf-C, had a tensile strength of $2165 \mathrm{MN} / \mathrm{m}^{2}$ (314 ksi) at $1093^{\circ} \mathrm{C}\left(2000^{\circ} \mathrm{F}\right)$ which is more than 6 times as strong as the strongest nickel or cobalt base superalloy. The ultimate tensile strength values obtained for the tungsten alloy wires were much higher than those obtained for molybdenum, tantalum or niobium alloy wire. When density is taken into account, the tungsten alloy wires show a decrease in advantage compared to tantalum, niobium or molybdenum wire, Fig. 2. However, the high strength tungsten alloy wires as well as molybdenum wires offer the most promise.

The elevated stress-rupture strength of reinforcing wire is more significant than the tensfle strength, since the intended use of the material is for long time applications. The $100 \mathrm{hr}$ rupture strength at 1093 and $1204{ }^{\circ} \mathrm{C}(2000$ and $2200^{\circ} \mathrm{F}$ ) is plotted for the various wire materials and compared to superalloys in $\mathrm{Fig}$. 3. The rupture strength of tungsten alloy fibers was increased by a factor of 3 at $1093{ }^{\circ} \mathrm{C}\left(2000^{\circ} \mathrm{F}\right.$ ) from about $434 \mathrm{MN} / \mathrm{m}^{2}$ (63 ks 1 ) for $218 \mathrm{CS}$ tungsten to $1413 \mathrm{MN} / \mathrm{m}^{2}(205 \mathrm{ksi})$ for $\mathrm{W}-\mathrm{Re}-\mathrm{Hf}-\mathrm{C}$ wire. The tungsten alloy wire was superior in stress-rupture strength to the other refractory wire materials with the exception of a tantalum alloy, ASTAR $811 \mathrm{C}$, which was stronger than most of the tungsten alloy materials at $1093^{\circ} \mathrm{C}\left(2000^{\circ} \mathrm{F}\right)$. The strongest tungsten alloy wire, W-Re-Hf-C, was over 16 times as strong as superalloys at $1093^{\circ} \mathrm{C}\left(2000^{\circ} \mathrm{F}\right)$. The $100 \mathrm{hr}$ rupture strength to density values for refractory metals wires and superalloys are plotted in Fig. 4 . Again the stronger tungsten wire materials are superior to the other refractory metal wires. When density is taken into account, the strongest tungsten wire material, W-Re-Hf-C, is more than 7 times as strong as the strongest superalloys at $1093{ }^{\circ} \mathrm{C}\left(2000^{\circ} \mathrm{F}\right)$. 
The processing schedules used to fabricate the newer high strength wires were not optimized to provide maximum strength at 1093 and $1204{ }^{\circ} \mathrm{C}(2000$ and $\left.2200^{\circ} \mathrm{F}\right)$. Much more work is needed to maximize their properties. Considerable opportunity exists to develop wire processing schedules tailored for fibermatrix composite use. The eventual application of TFRS composites will justify the added effort to further improve wire properties.

\section{MATRIX-ALLOY DEVELOPMENT}

The matrix is the exposed component of fiber reinforced composites and therefore must be able to withstand high temperatures and an environment which can result in catastrophic oxidation and hot corrosion. The primary function of the matrix is to bind the fibers into a useful body and to protect the fibers from oxidation and hot corrosion. The matrix must be relatively ductile compared to the fibers to facilitate load transfer from the matrix to the fiber. It also must be capable of evenly redistributing local stress concentrations and resisting abrasion and impact damage from foreign objects. The matrix and reinforcing fiber must be able to co-exist without mutualiy induced degradation that can result from chemical interactions that can reduce both the fiber and matrix properties. The most important factor in the initial selection of matrix composition is the ability of the matrix to form a good bond with the fiber without excessive reaction occuring which could degrade the fibers properties.

For high temperature use, nickel-base, cobalt-base and iron-base superalloys are preferred as the matrices for refractory metal fiber composites because they have demonstrated strength and ductility at elevated temperatures, as well as good oxidation and hot corrosion resistance.

A large proportion of the research effort conducted on refractory fiber composites has been on fiber-matrix compatiblitity. Efforts have focused on developing structurally stable composites by choosing a matrix composition 
which does not severely degrade the properties of the reinforcing fiber. One of the first systematic examinations to determine the effect of alloying reactions on the strength and microstructure of refractory metal fiber composites was reported by Petrasek and Weeton (1963) where copper-based binary alloys were used as a matrix for tungsten-fiber composites. The effects of alloying element additions to copper on the strength and microstructure of tungsten fiber composites were compared with mutaliy insolubie pure copper matrix composites exposed under the same conditions. The alloying elements studied were aluminum, chromium, cobalt, nfobium, nicke1, zirconium and titanium. Data obtained for solute elements in this system can be related to the expected behavior of these same elements in superalloys. These effects served as the basis for modifying superalloy matrix composition to control fiber-matrix reaction. Three types of fiber-matrix reaction were found to occur: diffusion-penetration reaction accompanied by a recrystallization of a peripheral zone of the tungsten fiber; (2) precipitation of a second phase with no accompanying recrystallization; (3) a solid solution reaction with no accompanying recrystallization in the fiber. Peripheral recrystallization was caused by diffusion of cobalt, aluminum, or nickel into the tungsten wire. Compound formation occurred with titanium and zirconium. Chromium and niobium in copper formed a solid solution with tungsten with no accompanying recrystallization of the tungsten fiber. The greatest damage to composite properties occurred with the penetration-recrystallization reaction while the two-phase and solid solution reactions caused relatively little damage. Recrystaliization of tungsten fibers in a $\mathrm{Cu}-10$ percent $\mathrm{Ni}$ matrix is shown in Fig. 5 .

Similar results were later found in a number of studies conducted on nickel-induced recrystallization of tungsten fibers, (Gruenting and Hofer, 1974; Hoffman et a 1., 1974; and Montelbano et al., 1968). Recrystalitzation could be induced at low temperature by the presence of solid nickel on the 
surface of the tungsten wire. Once initiated, nickel-induced recrystallization required a continued source of nickel for propagation of the recrystallization front. Work reported by Montelbano et al. (1968) found that palladium, aluminum, manganese, platinum and iron also greatly lowered the recrystallization temperature of tungsten.

Based on such findings, superalloy matrix compositions were developed that caused limited reaction with the fiber and minimal fiber-property loss (Petrasek et al., 1968). These superalloys contained high weight percentages of refractory metals to reduce diffusion penetration of nickel into tungsten. Additions of $\mathrm{TH}$ and $\mathrm{Al}$ to the matrix were also made to form intermetalic compounds which would further reduce the diffusion of nickel into tungsten. A typical matrix alloy that was developed was $\mathrm{Ni}-25 \mathrm{~W}-15 \mathrm{Cr}-2 \mathrm{Al}-\mathrm{Ti}$. The fiber stress to cause rupture in $100 \mathrm{hr}$ at $1090^{\circ} \mathrm{C}\left(2000^{\circ} \mathrm{F}\right)$ was reduced only 10 percent in composites using this alloy as a matrix compared to the equivalent fiber rupture strength tested in a vacuum outside a composite.

The problem of obtaining structure-stable composite materials from the nickel-tungsten and nickel-molybdenum systems were further examined by Karpinos et a1. (1972). The results obtained showed that in reinforced metal composite materials, in which the matrix and fiber form restricted solid solutions in the absence of intermetalic compounds, minimal fiber dissolution can be achieved by alloying the matrix with the fiber metal up to a concentration that is close to the solubility limit. However, when the matrix and the fiber react to form intermetalic compounds, matrix saturation is not effective in controlling fiber attack by dissolution.

The effect of the composition of nickel, cobalt and iron-base alloys on the structural stability of composite materials reinforced with tungsten fibers was determined by several investigators (Brentnal1, 1976; Klypin et a)., 1977; 
and M1rotvorskil and 01 'shevsk11, 1976, 1978, and 1979). The rate of interaction between the fiber and the matrix was determined from the extent of recrystallization of the fiber; the formation of intermediate phases at the interface; the solution of the fiber in the matrix; and the formation of diffusional porosity.

Fiber reinforced binary and multicomponent cobalt-base alloys were found to have a strong propensity to intermetaliic compound formation at the matrix fiber interface. Complex alloying additions to iron-base alloys were found to offer a means of suppressing fiber recrystallization and the formation of intermetallic compounds at the interface between the tungsten fibers and the ironbase matrix. Results of the reaction of tungsten fibers with binary alloys of iron, nickel, and cobalt annealed at 1200 and $1300^{\circ} \mathrm{C}\left(2190\right.$ and $2370{ }^{\circ} \mathrm{F}$ ) for $1 \mathrm{hr}$ (Mtrotvorskit and 01 'shevski1, 1979) are summarized in Table III. Shown in Table III are the number of compositions investigated for each matrix system and the relative number of cases, based on a percentage, that results in the following reactions with the tungsten fiber; recrystallization; formation of an intermetalilc compound; a diffusional penetration into the fiber; and no detectable recrystallization or reaction with the fiber. The tungsten fibers were found to be least reactive in iron-base alloy matrices. A number of matrix compositions have been identified, particularly for iron-base alloys, in which no detectable reaction occurs with tungsten fibers after short time exposures at temperatures up to $1200^{\circ} \mathrm{C}\left(2190^{\circ} \mathrm{F}\right)$.

Recent studies by Caulfield (1986) and Caulfield et al. (1985) have centered on minimizing reaction zone growth in TFRS composites for long-term applications $(>10 \mathrm{hr})$ in the temperature range of 1050 to $1200^{\circ} \mathrm{C}\left(1920\right.$ to $\left.2190{ }^{\circ} \mathrm{F}\right)$ by modifying matrix alloy chemistries. The kinetics and rate controlling process for reaction zone growth were ascertained by direct application of the moving boundary equations to reaction zone growth. Their results show that 
reaction zone growth is rate controlled by interdiffusion across the reaction zone and that the interdiffusion coefficient of the reaction zone phase, and thus the kinetics for reaction growth, are matrix chemistry dependent.

Table IV is a list of the parabolic rate constants, $K_{r z}(T)$, for reaction zone growth for various $W$-fiber/metal matrix composites. The tabulated data reveal that the kinetics of reaction zone growth substantially decrease with simultaneous increases in the matrix $\mathrm{Ni}$ content and decreases in the matrix $\mathrm{Fe}$ and co content. Since the Waspaloy matrix TFRS composite exhibited the slowest reaction zone kinetics, a cobalt-free modified Waspaloy matrix alloy was investigated. The results are unpublished to date; however, preliminary analysis of the co-free modified Waspaloy composite reveals that reaction zone kinetics are at least three times slower than those exhibited by the waspaloy matrix/W-fiber composite (T. Caulfield, A.B. Rodriguez, and J.K. Tien, present study at (Columbia University, New York, 1987).

Most of the matrix compositions investigated that resulted in minimum reaction with the fibers involved the formation of intermetallic compounds which served to reduce interdiffusion. Thus, intermetaliics might be sought as a natural occurring diffusion barrier. Use of a suitable protective barrier between the fiber and matrix offers the possibility of a wider range of composition selection for composites for high temperature application. However, the introduction of a second interface and a deposited coating, whose possible breakdown in service at high temperatures would cause a catastrophic decrease in strength, is not an attractive alternative to aircraft engine manufacturers and operators (Morris and Burwood-Smith, 1971). Although diffusion barrier coatings on reinforcing wire are a potentially effective way to achieve control of fiber-matrix interaction, techniques attempted to date have not resulted in reproducible, successful barrier coatings for refractory alloy wire (Signorelli, 1972). Optimism continues, however, that such natural or deposited coatings 
are possible and will offer increases in both strength and use temperature. Trade-offs in compound composition and ductility offer a fruitful area for continued studies.

\section{COMPOSITE FABRICATION}

The consolidation of matrix and fibers into a composite material with useful properties is one of the most difficult tasks in developing refractorywire-reinforced superalloys. Fabrication methods for refractory-wire-superally composites must be considered to be in the laboratory phase of development. Production techniques for fabrication of large numbers of specimens for extensive property characterizations have not yet been developed.

Fabrication methods can be classified as either solid phase or liquid phase depending upon the condition of the matrix phase during its penetration into a fibrous bundle. Liquid phase methods consists of casting the molten matrix using investment casting techniques so that the matrix infiltrates the bundle of fibers in the form of parallel stacks or mats. The molten metal must wet the fibers, form a chemical bond and yet be controlled so as not to degrade the fibers by dissolution, reaction, or recrystalitization.

Study and development of liquid phase fabrication techniques, (Ahmed and Barranco, 1977; Glenny, 1970, and Morris and Burwood-Smith, 1971), has revealed that large fibers and short liquid phase contact times are beneficial. The potential low cost of casting is appealing but reaction induced fiber property loss and limited fiber orientation control limit the applicability.

Solid phase processing requires diffusion, which is time-temperature dependent. Solid phase processing temperatures are much lower than liquid phase processing temperatures; diffusion rates are much lower and reaction with the fiber can be less severe. The prerequisite for solid state processing is that the matrix be in either wire, sheet, foil, or powder form. Hot pressing 
or cold pressing followed by sintered is used for consolidation of the matrix and fiber into a composite component.

Use of matrix materials in the form of sheet or foil involves placing the reinforcing fibers between layers of the matrix sheet or foll which are then pressed together. They may be hot pressed or alternately cold pressed followed by diffusion bonding. An example of this type of processing is reported by Karpinos et a1. (1975). One of the most promising methods of manufacture of composite sheet materials is that of vacuum hot rolling, which gives high productivity and enables large sized sheets to be manufactured. A study was reported of the processing parameters for the manufacture of composite sheet material by vacuum hot rolling (Severdenko, 1974).

The powder metallurgy approach is one of the most versatile methods for producing refractory fiber-superalloy composites and has yielded some excellent results. Almost all alloy metals can be produced in powder form. However, the large surface area of the fine powders is easily contaminated and introduces impurities that must be removed. High capital cost equipment is necessary to apply pressure and temperature in an inert atmosphere. Most powder-fabration techniques limit fiber content to 40 to 50 vol \%. Despite these disadvantages, powder processing has been used to achieve control of matrix-fiber reactions and has resulted in excellent composite properties.

Slip casting of metal alloy powders around bundles of fibers followed by sintering and hot pressing was developed for the solid state fabrication of refractory fiber-superalloy composites (Petrasek et al., 1968). Slipcast slurries of a mixture of powders and an organic gel in water were used to form a solid "green" composite which was subsequently sintered and then isostatically hot pressed to full density. This method is capable of achieving good matrix consolidation and bonding between fiber and matrix without excursions into the liquid metal region which would greatly increase fiber matrix reactions. 
Although this technique has demonstrated excellent success for uniaxially reinforced specimens, it is not regarded as an ideal method for component fabrication because most applications require some cross-ply fiber orientation, which is not easily accomplished with siip casting.

A fabrication procedure was developed utilizing solid phase processing in which fiber distribution, alignment, and fiber-matrix reaction could be accurately controlled (Brentnall and Toth, 1974). Matrix alloy powders were blended with a small quantity of organic binder (Teflon) and warm rolled into high density sheets. During rolling the Teflon formed an interlocking network of fibers which held the powder particles together. Fiber mats were made by winding the fibers on a drum, and then spraying them with a binder. The fiber array was cut from the drum and flattened to form a fiber mat. Precollimated fibers in mat form were sandwiched between layers of matrix powder sheet and the material was densified and extruded between fibers by hot pressing. Fibermatrix and matrix-matrix metallurgical bonding was achieved while preserving uniform fiber distribution and eliminating any voids. This procedure results in the fabrication of a single layer of fibers contained in the matrix material which was termed a monotape.

Arc spraying represents the most versatile form of composite fabrication. Arc spraying is a economical process for high temperature monotape fabrication developed at NASA Lewis (Westfal1, 1985), Fig. 6. Molten matrix alloy droplets are sprayed in a controlled atmosphere chamber onto a cylindrical drum wrapped with fibers. The drum is rotated and translated within the chamber in front of the spray to produced a controlled porosity monotape. Monotapes can then be cut into any shape desired with any orientation of fiber desired and subsequently stacked up and hot pressed into any desired layup. 


\section{COMPOSITE PROPERTIES}

The principal reason for most of the work on refractory fiber superalloy composites has been to produce a material capable of operation as highly stressed components such as turbine blades in advanced afrcraft and industrial gas turbine engines at temperatures of 1100 to $1200^{\circ} \mathrm{C}\left(2010\right.$ to $2190{ }^{\circ} \mathrm{F}$ ) or higher. Such an increase in temperature above the current limit of about $950^{\circ} \mathrm{C}\left(1740^{\circ} \mathrm{F}\right)$ for superalloy would permit higher turbine inlet temperatures and markedly decreased cooling requirements, thus improving engine performance and efficiency. An increase in blade temperature of $50^{\circ} \mathrm{C}\left(90^{\circ} \mathrm{F}\right)$ over current limits would be considered a significant improvement (Glenny, 1970). A review of gas turbine blade material property requirements (Endres, 1974; Glenny and Hopkins, 1976; and Stetson et al., 1966) indicates creep resistance, stressrupture strength, low-cycle fatigue, thermal fatigue resistance, impact strength, and oxidation resistance as properties of primary concern for turbine blade application. The following section reviews the results obtained for refractory fiber/superalloy composites to meet these critical property requirements.

\section{STRESS-RUPTURE STRENGTH}

At temperatures of $1100{ }^{\circ} \mathrm{C}\left(2010^{\circ} \mathrm{F}\right)$ and above, a superalloy matrix contributes very iittle to the rupture strength of the composite compared to the contribution of the refractory fibers. Fiber stress-rupture strength, volume fraction of fiber, and the degree of fiber-matrix reaction all control the stress-rupture strength of the composite. Figure 7 is a plot comparing the $100 \mathrm{hr}$ rupture strength at $1093^{\circ} \mathrm{C}\left(2000^{\circ} \mathrm{F}\right)$ for various fibers and composites containing 70 vol $\%$ of these fibers (Petrasek and Signore 111,1970 and 1974; and Petrasek et al., 1968). The matrix composition $(\mathrm{Ni}-15 \mathrm{Cr}-25 \mathrm{~W}-2 \mathrm{Al}-\mathrm{Ti})$ was the same for all of the composites and as indicated in the plot, the stronger the fiber the greater the stress-rupture strength of the composite. The effect 
of fiber content on the stress-rupture strength of a composite is shown in Fig. 8, (Dean 1967). Stress-rupture strength increases linearly as the fiber content increases.

A comparison of the $100 \mathrm{hr}$ rupture strength at $1093^{\circ} \mathrm{C}\left(2000{ }^{\circ} \mathrm{F}\right.$ ) for some of the composite systems that have been investigated, (Ahmad and Barranoio, 1977; Brentna 11, 1976; Chubarov et a)., 1972; Dean, 1967; Friedman and Fleck, 1979; Morris and Burwood-Smith, 1970; Petrasek and Signore111, 1970 and 1974; and Petrasek et al., 1968) is given in Table $V$ and plotted in Fig. 9 . Where possible, comparisons were made for composites containing 40 vol $\%$ fiber. It should be noted that higher values would be obtained for these composite systems if the fiber content was increased. Also shown in the plot are the values for the $100 \mathrm{hr}$ rupture strength for unreinforced alloys and for the strongest commercially avallable superalloys. The $100 \mathrm{hr}$ stress-rupture strength of all of the alloys investigated was substantially increased by the addition of tungsten fibers. All of the 40 vol \% fiber composites had a $100 \mathrm{hr}$ rupture strength greater than that for the strongest commercially available superalloys. The W-Hf-C fiber composite system is the strongest composite systems obtained to date. A 40 vol \% W-Hf-C fiber content superalloy composite is over 3 and $1 / 2$ times as strong in rupture for $100 \mathrm{hr}$ at $1100^{\circ} \mathrm{C}\left(2010^{\circ} \mathrm{F}\right)$ as the strongest commerically avallable superalloys. The composite containing a larger amount of fiber reinforcement ( 56 vol * $\mathrm{W}-1$ percent ThO ${ }_{2}$ wire) in FeCrAly also had an impressive stress-rupture strength, over 2 and $1 / 2$ times that for the strongest commercially avallable superalloys.

The density of these composite materials is greater than that of superalloys and this factor must be taken into consideration. The stresses in turbine blades, for e.g., are a result of centrifugal loading; therefore, the density of the material is important. A comparison of the specific strength properties of composites and superalloys is therefore significant. Figure 10 
is a plot comparing the values of the $1100^{\circ} \mathrm{C}\left(2010^{\circ} \mathrm{F}\right) 100 \mathrm{hr}$ rupture strength to density ratios for composites and superalloys. The plot shows that even when density is taken into account, the stronger composites are still much superior to the strongest commerically available superalloys. The composites containing 40 vol \% W-Hf-C wire is almost 2 and $1 / 2$ times as strong as the strongest superalloys.

The comparisons of stress-rupture strength between composites and superalloys is even more favorable for the composite when long application times are involved. Figure 11 is a plot of stress to rupture versus time to rupture for three different fiber compositions, each having the same matrix material, compared to the strongest superalloys. All of the fiber composite systems are stronger relative to superalloys for rupture in $1000 \mathrm{hr}$ than for rupture in $100 \mathrm{hr}$ at $1093^{\circ} \mathrm{C}\left(2000^{\circ} \mathrm{F}\right)$. The stress (to cause rupture) to density ratio versus time to rupture is plotted in Fig. 12. The specific stress-rupture strength advantage for the composite also increases with time to rupture. The 40 vol \% tungsten fiber compostte, e.g., has about the same specific (density corrected) strength for rupture in $100 \mathrm{hr}$ compared to superalioys but is almost twice as strong as superalloys for rupture in $1000 \mathrm{hr}$. For currently requtred blade lives of 5000 to $10000 \mathrm{hr}$ this advantage becomes even greater.

A comparison of the range of values for the $100 \mathrm{hr}$ rupture strength for tungsten fiber reinforced superalloy composites tested at $1093^{\circ} \mathrm{C}\left(2000^{\circ} \mathrm{F}\right)$ with the range for the stronger cast superalloys as a function of temperature is shown in Fig. 13. The strongest TFRS composite has the same rupture strength at $1093^{\circ} \mathrm{C}\left(2000^{\circ} \mathrm{F}\right)$ as does the strongest superalloy at $915^{\circ} \mathrm{C}\left(1680^{\circ} \mathrm{F}\right)$.

This represents a material use temperature advantage for the composite of $145^{\circ} \mathrm{C}$ $\left(320^{\circ} \mathrm{F}\right)$ compared to the strongest superalloy. Figure 14 shows the density corrected values for rupture in $100 \mathrm{hr}$ as a function of temperature. When density 
is taken into consideration the composite has a material use temperature advantage of $110^{\circ} \mathrm{C}\left(200{ }^{\circ} \mathrm{F}\right)$ over the strongest superalloys.

\section{CREEP RESISTANCE}

The creep-rupture properties Nimocast $713 \mathrm{C}$ reinforced with tungsten or tungsten-5 percent rhenium wire were evaluated and compared with the data determined for vacuum-cast Nimocast 713C, (Morris and Burwood-Smith, 1970). Typical composite creep curves are shown in Fig. 15 together with a comparattve curve for the unreinforced matrix. The creep curves for both materials exhibit the three characteristic stages of creep associated with conventional materials. Essentially, reinforcement reduces the second stage minimum creep rate markedly for a given applied stress due the presence of the more creep resistant fibers. The reduction in minimum creep rates observed on reinforcing Nimocast $713 \mathrm{C}$ suggests that the stronger, more creep resistant component, the fiber, controls the creep behavior. The lack of evidence of creep deformation in the matrix of the composite, except at the matrix-fiber interface adjacent to the fracture surface, also suggested that the behavior is controlled by the reinforcement. Simllar results were obtained with tungsten-1 percent $\mathrm{ThO}_{2}$ refnforced Hastelloy $x$ composites (Baskey, 1967), tungsten-1 percent $\mathrm{ThO}_{2}$ reinforced FeCrAlY composites (Brentna11, 1976), and with tungsten-nickel composites (Kannappan and Fischmeister, 1975).

\section{FATIGUE}

High-temperature materials in gas turbines are subject to cyclic stresses and strains. These can lead to the development of cracks and fallures which conventionaliy are discussed in three separate groupings, depending on the magnitude and cause of the stresses:

High-cycle fatigue

Low-cycle fatigue 
Thermal fatigue

(a) High Cycle Fatigue

High-cycle fatigue tests have been conducted on $\mathrm{W}-1$ percent $\mathrm{ThO}_{2} / \mathrm{Hastelloy}$ $X$ composite specimens (Baskey, 1967). Fatigue tests were performed using direct stress, tension-tension, axially loaded specimens. The stress to cause fatlure in $1 \times 10^{6}$ cycles versus temperature is plotted in Fig. 16. Unreinforced Hastelloy $x$ data are plotted for comparison. The composites were stronger at all temperatures, ranging from 1.2 times as strong at room temperature to 4 times as strong at $980^{\circ} \mathrm{C}\left(1800^{\circ} \mathrm{F}\right)$. The ratio of fatigue strength to ultimate tensile strength for the same materials is plotted in Fig. 17 . For all test temperatures, the ratio for the composite was higher than that for the Hastelioy $x$, indicating that high-cycle fatigue resistance of the composite is controlled by the fiber.

The high-cycle fatigue strength for $W-1$ percent $\mathrm{ThO}_{2} / \mathrm{FeCrA}$ Y composites was determined at 760 and $1039^{\circ} \mathrm{C}\left(1400\right.$ and $\left.1900^{\circ} \mathrm{F}\right)$ in (Fleck, 1979). Fatigue tests were performed using direct tension-tension, axially loaded specimens. Figure 18 is a plot of maximum stress versus the number of cycles to failure for specimens tested at $760^{\circ} \mathrm{C}\left(1400^{\circ} \mathrm{F}\right)$. The maximum stress versus number of cycles to fallure for specimens tested at $1038{ }^{\circ} \mathrm{C}\left(1900{ }^{\circ} \mathrm{F}\right)$ is plotted in Fig. 19. The results again indicate that fatigue is controlled by the fiber.

Figure 20 is a plot of the $1 \times 10^{6}$ cycle fatigue strength to ultimate tensile strength ratio for some superalloys and the range of values obtained for TFRS composites showing that the composites' response to high-cycle fatigue is superior to that for superalloys. Push/pull and reverse bend fatigue strength data were determined for a W/superalioy composite (Dean, 1967). The fatigue strength measured in push/pull tests at 20,300 , and $500{ }^{\circ} \mathrm{C}(70,570$, and $930^{\circ} \mathrm{F}$ ) was substantially increased by the introduction of 40 vol \% 
tungsten wires. With cantilever specimens tested in reverse bending, a significant increase in fatigue strength also resulted from the incorporation of tungsten wires.

(b) Low-Cycle Fatigue

Limited work has been reported on the low cycle fatigue behavior of refractory fiber/superalloy composites. The low cycle fatigue behavior for tungsten fiber reinforced nickel was determined at room temperature (Nilsen and Sovik, 1974). Specimens containing 11 to 25 vol \%, $500 \mu \mathrm{m}(0.020$ in.) diameter, tungsten fibers or 20 to 28 vol \%, $100 \mu \mathrm{m}(0.004 \mathrm{in.})$ diameter, tungsten fibers were fabricated by a liquid metal inflitration process and tested in fatigue. Specimens containing 8 or 10 vol \% of $300 \mu \mathrm{m}(0.012 \mathrm{in.})$ diameter tungsten fibers were fabricated by a powder and subsequent forging process and also tested in fatigue. Fatigue tests were performed at about $150 \mathrm{~Hz}$ using direct stress, tension-tension, axially loaded specimens. Figure 21 is a plot of the ratio of the maximum stress for fatigue failure to ultimate tensile strength for the range of cycles investigated. The observed fatigue ratios shown for the com- posite specimens were much higher in comparison to some superalloys referenced by the author. The fatigue ratio reported for Nimocast $713 \mathrm{C}$ for $10^{8}$ cycles was 0.24 and for Incoloy 901 and Udimet 700 for $10^{7}$ cycles the ratio was 0.14 and 0.17 , respectively. As shown in $\mathrm{Fig} .21$ the fatigue ratio obtained for the composites was greater than 0.65 at $10^{6}$ cycles.

Low-cycle fatigue tests were conducted at 760 and $980^{\circ} \mathrm{C}\left(1400\right.$ and $\left.1800{ }^{\circ} \mathrm{F}\right)$ on 20 and 35 vol \% W-1 percent ThO $\mathrm{W}_{2}$ fiber reinforced FeCrAlY composites, (Fleck, 1979). Fatigue tests were performed at $0.65 \mathrm{~Hz}$ and a stress cycle of from $5.5 \mathrm{MN} / \mathrm{m}^{2}(0.8 \mathrm{ks} 1)$ to a maximum stress. The load ratio, $\mathrm{R}$, was $\sim 0.01$ and the stress ratio, A, was 1 . The low-cycle fatigue results are plotted in Fig. 22. The results indicate that the fiber controls low cycle fatigue 
strength as was the case for high-cycle fatigue behavior. The 35 vol \% fiber content specimens had much higher values of fatigue strength versus cycles to fallure than did the 20 vol \% percent fiber specimens. The ratio of fatigue strength to ultimate tensile strength versus cycles to fallure is plotted in Fig. 23. Very high values were obtained at both 760 and $980{ }^{\circ} \mathrm{C}(1400$ and $1800^{\circ} \mathrm{F}$ ) indicating that the composite has a higher resistance to low cycle fatigue in this temperature range.

(c) Thermal Fatigue

Thermal fatigue failures are caused by the repeated application of stress that is thermal in origin. Rapid changes in the temperature of the environment can cause transient temperature gradients in components. Such temperature gradients give rise to thermal stresses and strains. Thermal fatigue fallure is the cracking of materials caused by repeated rapid temperature changes.

Superimposed on stresses generated by temperature gradients, in the case of the composite, are internal stresses caused by the difference in expansion coefficlents between the fibers and matrix. The mean coefficient of thermal expansion from room temperature to $1100^{\circ} \mathrm{C}\left(2010^{\circ} \mathrm{F}\right)$ for superalloys ranges from 15.8 to $19.3 \times 10^{6} /{ }^{\circ} \mathrm{C}\left(8.8\right.$ to $\left.10.7 \times 10^{-6} /{ }^{\circ} \mathrm{F}\right)$ and is $\sim 5 \times 10^{-6} /{ }^{\circ} \mathrm{C}\left(2.7 \times 10^{-6}{ }^{\circ} \mathrm{F}\right)$ for tungsten. Because of the large difference in expansion coefficients between the fiber and matrix and the resulting strains, thermal fatigue is believed to be the most serious limitation on composite usefulness.

A number of investigators have developed analytical methods to calculate the dependence of composite deformation on cyclic, geometric, and constituent deformation parameters (Baranov and Yakovleva, 1975; Gaiduk et a1, 1972; and Garmong, 1974). The results of these calculations fllustrate the possible effects of several vartables on deformation damage parameters. Because of the difference in expansion coefficients, the matrix is strained in tension upon 
cooling and in compression upon heating while the fiber is strained in compresston upon cooling and tension upon heating.

Work reported by Garmong (1979), Indicates that the hystersis loop of matrix stress versus temperature caused by plastic deformation of the matrix due to the heating and cooling cycle stabilizes after a few cycles so that a steadystate plastic compression-tension fatigue results when no external stress is present. Total cycilic plastic strain increases by a law of the form, total strain = strain per cycle $x$ number of cycles. The ability of the matrix to accommodate plastic strain thus controls the number of cycles to failure for the composite if plastic deformation of the matrix governs the fallure mode of the composite in fatigue.

Three types of cycling damage have been noted to date: plastic flow of the fiber in compression, matrix fracturing and fiber-matrix interface debonding.

A number of studies have been conducted on the response of tungsten fiber/ superalloy composites to thermal cycling. Table VI compares the data obtained for several composite systems. Cylindrical specimens of 40 percent W/Nimocast 258 were cycled between room temperature and $1100^{\circ} \mathrm{C}\left(2010^{\circ} \mathrm{F}\right)$ in a fluidized bed to obtain rapid heating and cooling, (Dean, 1967). Metallographic examination after 400 cycles revealed no apparent damage at the fiber-matrix interface. Cylindrical specimens of W/Nimocast $713 C$ were cycled in a fluidized bed in the temperature ranges shown in Table V. (Morris and Burwood-Smith, 1971). Cracking occurred after relatively few cycles with the exception of the specimens cycled from 20 to $600^{\circ} \mathrm{C}\left(70\right.$ to $\left.1110^{\circ} \mathrm{F}\right)$. The bond between the fiber and matrix was reported to be severely degraded by thermal cycling to $1050^{\circ} \mathrm{C}$ $\left(1920^{\circ} \mathrm{F}\right)$. 
Thermal cycle tests were conducted on specimens of reinforced sheet materlal having a matrix of EI435 (Nichrome) (Dudnik et a1., 1973). The specimens were heated in an electric resistance furnace for 2.5 min up to a temperature of $1100^{\circ} \mathrm{C}\left(2010^{\circ} \mathrm{F}\right)$ followed by a water quench to room temperature. The number of cycles for debonding between the fiber and matrix to occur was determined as a function of fiber content. As shown in Table $V$ the number of cycles for debonding to occur decreased with increasing fiber content.

Tests were also conducted on reinforced EI435 sheet material by Banas et al. (1976). The specimens were heated by passage of an electric current. Irreversible deformation occurred after cycling for all of The 15 volume fiber content specimens but not for the 32 volume fiber content specimens. During the inftial stages of cycling, warpage and bending were observed. A length decrease was observed during the entire test. With an increase of the number of cycles the length and rate of the dimensional change diminished. Heat treatment had a considerable effect on dimensional instability of the composite. As a result of annealing the specimen their propensity for deformation during thermocycling decreased. Annealing reduced the yield strength of the matrix. The level of stresses arising in the fibers as a consequence of the difference in expansion coefficients was determined by the resistance to plastic deformation of the matrix. With a decrease in the yield strength of the matrix the level of stress on the fiber decreased and the fibers did not plastically deform.

Several different nickel base composite systems were thermally cycled in work reported by Brentnall and Moracz (1976). Specimens were heated by passage of an electric current. The specimens were heated to $1093^{\circ} \mathrm{C}\left(2000^{\circ} \mathrm{F}\right)$ in $1 \mathrm{~min}$ and cooled to room temperature in $4 \mathrm{~min}$. All of the 35 volume fiber content specimens were warped after 100 cycles, while the 50 vol \% fiber content specimens were not. The most ductile matrix materials NiCrAly showed the least 
amount of damage after 100 cycles. Specimens containing 30 vol $\% W-1$ percent $\mathrm{ThO}_{2}$ fibers in a matrix of FeCraly were exposed to 1000 cycies from room temperature to $1204^{\circ} \mathrm{C}\left(2200^{\circ} \mathrm{F}\right)$, (Brentnall et al., 1975). The specimens were heated up to $1204{ }^{\circ} \mathrm{C}\left(2200^{\circ} \mathrm{F}\right)$ in $1 \mathrm{~min}$ and cooled to room temperature in $4 \mathrm{~min}$. As shown in Fig. 24, surface roughening occurred, but there was no matrix or fiber cracking after the 100 cycle exposure.

As indicated in Table VI, a composite system has been identified, $W-1$ $\mathrm{ThO}_{2} / \mathrm{FeCrAly}$, that can be thermaliy cycled though a large number of cycles without any apparent damage. With the exception of the 40 percent W/Nimocast 258 composite system which withstood 400 cycles without any apparent damage, all of the other systems investigated indicated that some type of damage occurred. These systems would be limited to applications where the component would be exposed to very few thermal cycles. Only a limited number of systems have been investigated to date and a need exists to identify other thermal fatigue resistant systems. The results obtained indicate that a ductile matrix which can relieve thermaliy induced strains by plastic deformation is required for composite thermal fatigue resistance.

\section{IMPACT STRENGTH}

Composite materials must be capable of resisting impact fallure from foreign objects or from falled components that may pass through the engine if they are to be considered for use as aircraft engine blade or vane components.

Factors affecting the impact strength of tungsten fiber metal matrix composites were investigated by Winsa and Petrasek (1973). Miniature Izod and standard Charpy impact strength data were obtained for a tungsten fiber reinforced nickel base alloy $(\mathrm{N} 1-25 \mathrm{~W}-15 \mathrm{Cr}-2 \mathrm{Al}-\mathrm{Ti})$. It has been found that composTte properties as measured by the miniature Izod impact test correlate closely with composite properties as measured by various balistic impact tests and it was concluded that the miniature Izod test is a reasonable screening test for 
candidate turbine blade and vane materlal (Ohnysty and Stetson, 1967). The Izod impact strength of unnotched and notched specimens as a function of fiber content is plotted in Fig. 25 for two test temperatures, ( 75 and $1000^{\circ} \mathrm{F}$ ). Impact strength decreased with increasing fiber content at the lower temperature, but increased with increasing fiber content at the higher temperature.

Figure 25 is a plot of impact strength as a function of temperatures. There is a sharp increase in impact strength for the 60 vol $\%$ unnotched specimens at $260^{\circ} \mathrm{C}\left(500^{\circ} \mathrm{F}\right)$, which correspond to the ductile-brittle transition temperature (DBTT) for the fiber. In general, unnotched composites had higher impact strength, compared to the matrix, at temperature above the DBTT of the fiber and lower impact strength than the matrix below the OBTT of the fiber. The matrix's contribution to impact strength for the composite is most significant at low temperatures, whlle the fiber controls nigher temperature impact strength, above $260^{\circ} \mathrm{C}\left(500^{\circ} \mathrm{F}\right)$. The effect of fiber content on notch sensitivity was also determined. The ratio of the composite's notched impact strength per unit area to its unnotched impact strength per unit area is plotted as a function of fiber content in Fig. 27. The notch sensitivity of the composite decreased with increasing fiber content both above and below the DBTT of the fiber. Heat treatment or not rolling improved the room temperature impact strength of the composite. Heat treatment increased the impact strength of the notched unreinforced matrix by almost four times and nearly doubled the impact strength of a 45 vol $*$ fiber content composite. Rod rolling increased the impact strength of a 56 vol \% fiber content composite by nearly four times. The improved impact strength for the composite was related to improved matrix impact strength.

An additional objective of work conducted by Winsa and Petrasek (1973) was to determine if the potential impact resistance of tungsten fiber/superalloy composites was sufficlent to warrant their consideration as turbine blade or 
vane materials. Alloys with minfature Izod impact values less than $1.7 \mathrm{~J}$ (15 in. - / b) have been successfuliy run as turbine blades (Stgnorelli et al., 1956; and waters et a1., 1959). Based on this, the value of $1.7 \mathrm{~J}(15 \mathrm{in} .-1 \mathrm{~b})$ was taken as the minimum value for Izod impact strength to indicate if a material has promise for further evaluation leading to turbine blade use. Figure 28 compares the tungsten fiber/superalioy impact strength values with the minimum standard. At room temperature a fabricated composites containing fiber contents greater than 35 percent did not meet the minimum requirement. Heat treatment and hot working, however, improved the impact strength so that high fiber content composites met the minimum requirements. At $760^{\circ} \mathrm{C}$ $\left(1400^{\circ} \mathrm{F}\right)$, the higher fiber content as-fabricated composites have impact strengths distinctly above the minimum requirement. High Charpy impact strength values were obtained at $1093^{\circ} \mathrm{C}\left(2000^{\circ} \mathrm{F}\right), 37.3 \mathrm{~J}(330 \mathrm{in} .-1 \mathrm{~b})$ for a 60 vol \% fiber content specimen, implying that most of this strength is maintained to at least $1093^{\circ} \mathrm{C}\left(2000^{\circ} \mathrm{F}\right)$. The impact strength potential for tungsten fiber/superalloy composites thus appears adequate for some aircraft engine component applications, such as turbine airfoils and vanes.

\section{OXIDATION AND CORROSION}

The gaseous environment in the gas turbine engine is highly oxidizing with oxygen partial pressure of the order of 2 to $4 \mathrm{~atm}$, (El-Dahshan et a1., 1975). However, this environment also contains significant amounts of combustion product impurities inciuding sulfur from the fuel and alkalt salts ingested with the intake air. Under these conditions an accelerated oxidation may be encountered, sometimes, but not always, accompanied by the formation of sulfides within the alloy: this is commonly referred to as hot corrosion.

The basic design of the composite material assumes that the superalloy matrix will provide oxidation resistance, including protection of the tungsten 
fibers. Superalloys that are used for hot section engine components are oxidation resistant for material operating temperatures up to about $980{ }^{\circ} \mathrm{C}\left(1800^{\circ} \mathrm{F}\right)$. Above a material temperature of $980^{\circ} \mathrm{C}\left(1800^{\circ} \mathrm{F}\right)$ it is necessary to coat or clad the material to provide the required oxidation resistance. Claddings that are used for superalloy oxidation protection, such as NiCrAlY and FeCrAlY, are oxidation resistant to temperatures above $1090^{\circ} \mathrm{C}\left(2000^{\circ} \mathrm{F}\right)$. These materials may also be considered as the matrix for composites so that the composite would not have to be coated or clad for high temperature oxidation resistance. Preliminary oxidation studies were conducted on a nickel base superalloy reinforced with tungsten-1 percent ThO ${ }_{2}$ fibers and clad with Inconel by Petrasek and Signorelli (1970). The specimens were exposed in air at $1093^{\circ} \mathrm{C}\left(2000^{\circ} \mathrm{F}\right)$ for times up to $300 \mathrm{hr}$. Figure 29 is a transverse section of a clad composite specimen exposed for $50 \mathrm{hr}$ at $1093^{\circ} \mathrm{C}\left(2000^{\circ} \mathrm{F}\right)$. The Inconel cladding was oxidized, and a coherent oxide scale formed on the Inconel. oxidation had not progressed to the composite, and the surface fibers were not affected by the oxidation of the cladding. Composite specimens of $\mathrm{W}-1$ percent $\mathrm{ThO}_{2} / \mathrm{FeCrAlY}$ having completely matrix protected fibers were exposed to static air at 1038 , 1093 , and $1149^{\circ} \mathrm{C}\left(1900,2000\right.$, and $\left.2100^{\circ} \mathrm{F}\right)$ for up to $1000 \mathrm{hr}$. The weight change in $1000 \mathrm{hr}$ was $0.3 \mathrm{mg} / \mathrm{cm}^{2}$ for $1038^{\circ} \mathrm{C}\left(1900^{\circ} \mathrm{F}\right)$ and $1.25 \mathrm{mg} / \mathrm{cm}^{2}$ for $1149^{\circ} \mathrm{C}\left(2100^{\circ} \mathrm{F}\right)$. These values are in agreement with values obtained for the matrix material without any reinforcement (Wukusick, 1966). Oxidation did not progress to the surface fibers.

The oxidation and corrosion resistance of composite materials having exposed fibers is also an important consideration. Although the fibers in the composite would not be designed to be exposed to the engine environment an understanding of the high temperature oxidation and corrosion behavior is desirable in the event of a coating, cladding, or matrix fallure during service which could occur, e.g., from impact due to foreign objects passing through the 
engine. Figure 30 illustrates the principal paths for oxidation and corrosion of exposed fibers. Oxidation proceeding perpendicular to the fibers (through the blade or vane thickness) would destroy the exposed fibers, but intervening matrix would prevent oxidation of subsequent layers. Thus, only a partical loss of strength would result. Oxidation parallel to the fibers (along the blade or vane span) potentially is more severe, since all the exposed fibers in the transverse section potentially could be oxidized along their entire length. However, studies conducted to evaluate oxidation along fibers showed only limited oxidation penetration along the fibers (Brentnall et al., 1975; Dean, 1965; and E1-Dahshan et a1., 1975).

The hot corrosion behavior of tungsten fiber reinforced $\mathrm{N} i-20$ percent $\mathrm{Cr}$ composite specimens was also examined by El-Dahshan et al. (1975), under the following exposure conditions: (a) sulifidation in $\mathrm{H}_{2}-10$ percent $\mathrm{H}_{2} \mathrm{~S}$; (b) presulfidation in $\mathrm{H}_{2}-10$ percent $\mathrm{H}_{2} \mathrm{~S}$ followed by oxidation in oxygen; and (c) oxidation in 1 atmosphere of oxygen after precoating with $\mathrm{Na}_{2} \mathrm{SO}_{4}$. During sulifidation, only the matrix formed sulified and the fibers remained unaffected. Consequentiy, presulfidation, although having a dramatic effect on the oxidation of the matrix did not have a damaging effect on the fibers. The presents of sodium sulfate was also not critical. Thus, hot corrosion conditions were not harmful to the tungsten reinforced composites studied, and catastrophic loss of the exposed tungsten fibers did not occur upon exposure to a hightemperature oxidizing environment.

\section{$X$. THERMAL CONDUCTIVITY}

High thermal conductivity is desirable in a turbine blade material to reduce temperature gradients; this, in turn, results in reduced thermally induced strains that can cause cracks or distortion. In addition, higher thermal conductivity can reduce coolant flow requirements in some impingement 
cooled blades leading to greater engine efficiency or durability (Winsa et al., 1978).

The conductivity of tungsten fiber/superalloy composites is markediy superior to that of superalloys. The thermal conductivity of tungsten is much higher that for superalloys and the more tungsten added to a composite the greater the conductivity. Thermal conductivity of the composite is greatest in the direction of the fiber axes since there is a continuous path for conduction along the tungsten fibers. Conduction perpendicular to the fiber axes is lower because the heat cannot find a continuous path through tungsten. The thermal conductivity of some tungsten fiber/superalloy composites was determined as a function of temperature by winsa et al. (1978). Figure 31 shows the thermal conductivity values obtained for a composite containing 65 vol \% fibers in a nickel base alloy and tested in the direction of the fiber axis and for a composite containing 50 vol $\%$ and tested in the direction perpendicular the fiber axis. The longitudinal thermal conductivity is seen to be much higher than the transverse conductivity. Also shown in the figure are values for the matrix materials. The composites have much higher values for thermal conductivity over the entire temperature range.

\section{Composite Component Fabrication}

Having demonstrated adequate properties for application as a turbine blade materfal, the next area of consideration is whether complex shapes such as hollow turbine blades can be designed and fabricated from such material and at reasonable cost. The selected composite fabrication technqiues must result in a composite whose properties meet those required for application of the composite. The processes must be capable of first producing component shapes to required dimensions, second incorporating both unlaxial and off-axis fiber 
positioning; third providing uniform matrix cladding to prevent fiber oxidation, and fourth, providing if necessary, for cooling or weight reduction passages. The combined fabrication techniques must also be cost effective and reproducible.

Diffusion bonding of monolayer composite plies is currently the most promising, cost effective method of fabrication for complex shapes. The composite plies consist of aligned tungsten fibers sandwiched between layers of matrix material. This approach has the capability for accurate fiber distribution and alignment; moreover, it limits fiber-matrix interdiffusion during fabrication. This approach also is capable of producing blade shapes that are close to final dimensions; hence, only limited machining and touch up grinding is needed (Mazzel et al., 1976; Melnyk and Fleck, 1979; and Petrasek et al., 1979).

The feasibility of composite component fabrication, was successfully demonstrated (Melnyk and Fleck, 1979). A JT90-7F first stage, convection cooled turbine blade was selected as the model from which a $\mathrm{W}-1$ percent $\mathrm{ThO}_{2} / \mathrm{FeCrAlY}$ composite blade was designed. The major purpose of the fabrication effort was not only to demonstrate the feasiblitty of fabricating a complex shape but to also demonstrate that design requirements could be met in the fabricated blade. The design features incorporated into the fabricated blade are Indicated in Figs. 32 and 33 .

Figure 34 shows the fabrication sequence used to produce the hollow composite turbine blade. A tungsten fiber mat was sandwiched between powder sheets of Fecraiy which was subsequently hot pressed to form a monotape. The monotape was then cut into the plies necessary to arrive at the final blade dimension. The plles wee then stacked around a steel core. Root inserts and outserts could also be stacked around the assembiy or could be attached in a 
secondary fabrication step. The entire assembly was then placed in a refractory metal die, heated and pressed to arrive at the proper airfoll contour. After pressing the steel core was removed by leaching out with an acid. A tip cap was then was welded on to the end of the airfoil and an impingement cooling insert was placed in he leached out cavity and brazed in the root of the blade. Figure 35 shows the as fabricated $W-1$ percent Tho 2 /FeCrAlY composite hollow JT9D-7F airfoil containing a bonded on end cap and trafling-edge coolant slots. Figure 36 shows the composite airfoil which was brazed to a high strength superalloy arc root. A cross section of the composite airfoil is shown in Fig. 37. Excellent fiber alignment and fiber distribution was obtained and the fibers were fuliy protected by a layer of Fecraly on the interior and exterior surfaces of the airfoil.

Successful fabrication of a hollow composite airfoil has demonstrated that this material can be fabricated into the complex design shapes for hot turbine section components. While components such as vanes or combustion liners have not been fabricated these components are less complex than the blade and can be considered for future programs.

The fabrication process sequence used to produced a hollow composite blade was used in a fabrication cost study (Barth et al., 1977). Fabrication costs were estimated for high technology turbine blade fabricated using thee different materials. The same turbine blade configuration, a first stage JT9D-7F blade was used for each material. Directionally solidified eutectic (DSE), an oxide dispersion strengthened superalloy (ODSS), and $W-l$ percent Tho 2 FeCrAlY blade manufacturing costs were compared with the cost of producing the same blade from a directionally solidified (DS) superalloy, the current blade material. The relative costs are shown in Fig. 38. The study indicates that W/Fecraly 
manufacturing cost should be competitive with current manufacturing costs of manufacturing this blade by directional solidification of a superalloyprovided the projected manufacturing yields can be realized in actual commerical production of blades.

\section{CONCLUDING REMARKS}

Exploratory development and material property screening have indicated that tungsten fiber reinforced superalloy composites have considerable potential for application as advanced high temperature material. Studies of a wide range of physical and mechanial properties in laboratory tests have demonstrated the advantage of tungsten fiber reinforced superalloy composites over conventional superalloys. Also computer simulations and evaluations of superalloy composite performance as engine components have indicated the potential for significant temperature and strength increases. Moreover, blade fabrication studies have demonstrated the feasibility of producing complex hollow shapes at a cost competitive with directionally solidified superalloy blade costs. Still, a great deal of work remains to be done on this family of materials to aid in its transition from laboratory feasibility to rig testing of prototype hardware and then on manufacturing technology and detafled design. 
1. Ahmad, I., and Barranco, J.M. (1977). SAMPE Q. 8 , 38-49.

2. Amra, L.H., et al. (1970). "Development of Fabrication Process for Metallic Fibers of Refractory Metal Alloys." NASA CR-72654.

3. Banas, F.P., Baranov, A.A., and Yakovleva, E.V. (1976). Strength Mater. 7, $744-748$.

4. Baranov, A.A., and Yakovleva, E.V. (1975). Strength Mater. 7 , 966-969.

5. Barth, C.F., Blake, D.W., and Stetson, T.S. (1977). "Cost Analysis of Advanced Turbine Blade Manufacturing Processes." TRW-ER-17930, TRW InC., Cleveland, OH. (Also, NASA CR-135203).

6. Baskey, R.H. (1967). "Fiber-Reinforced Metallic Composite Materials," AFML-TR-67-196, Air Force Matertals Lab., Wright Patterson AFB, OH,

7. Brentna 11, W.D., (1976). "Metal Matrix Composites for High Temperature Turbine Blades," TRW-ER-7790-F, TRW Inc., Cleveland, OH. (Also, NAOC-76225-30, Naval Air Development Center).

8. Brentnal1, W.D., and Moracz, D.J. (1976). "Tungsten Wire-Nickel Base Alloy Composite Development." TRW ER-7849, TRW Inc., Cleveland, OH. (Also, NASA (R-135021).

9. Brentna11, W.D., and Toth, I.J., (1974). "Fabrication of Tungsten Wire Reinforced Nickel-Base Alloy Composites." TRW-ER-7757, TRW Inc.,

Cleveland, OH. (Also, NASA CR-134664).

10. Brentna 11, W.D., Moracz, D.J., and Toth, I.J. (1975). "Metal Matrix Composites for High Temperature Turbine Blades." TRW-ER-7722-F, TRW InC., Cleveland, $\mathrm{OH}$.

11. Caulfield, T. (1986). "Understanding the Interdiffusional Flux Related Effects on the High Temperature Compatiblitty of Tungsten Fiber Reinforced Superalloy (TFRS) Composites." PhD Thesis, Columbia University.

12. Caulfield, T., Bellows, R.S., and Tien, J.K. (1985). Metall. Trans. A. 16, $1961-1968$.

13. Chubarov, V. M., et a1. (1972). Strength Mater. $\underline{3}, 856-959$.

14. Dean, A.V. (1965). "The Refnforcement of Nickel-Base Alloys With High Strength Tungsten Wires," NGTE-R-266, National Gas Turbine Establishment, Pystock, England.

15. Dean, A.V. (1967). J. Inst. Met. $95,79-86$.

16. Dudnik, G.I., Banas, F.P., and Aleksandrov, B.V. (1973). Strength Mater. $\underline{5}, 106-107$.

17. ET-Dahshan, M.E., Whittle, O.P., and Stringer, J. (1975). Oxid. Met. 9, 45-67. 
18. Endres, W., (1974). In "High-Temperature Materlals in Gas Turbines" (P. R. Sahm and M. 0. Speidel, eds.) pp. 1-14. Elsevier Scientific, New York.

19. Fleck, J. N. (1979). "Fabrication of Tungsten-Wire/FeCrAlY - Matrix Composites Specimens." TRW-ER-8076, TRW Inc., Cleveland, $\mathrm{OH}$.

20. Friedman, G.I., and Fleck, J.N. (1979). "Tungsten Wire-Reinforced Superalloys for $1093{ }^{\circ} \mathrm{C}\left(2000^{\circ} \mathrm{F}\right)$ Turbine Blade Applications." TRW-ER-8135, TRW Inc., Cleveland, OH. (Also, NASA CR-159720).

21. Gaiduk, V.V., Lavrenko, A.S., and Sukhanov, Yu. V. (1972). Strength Mater. 4. $1143-1146$.

22. Garmong, G. (1974). Meta 11. Trans. ㄴ, 2183-2205.

23. Glenny, R.J.E. (1970). Proc. R. Soc. London A. 319, 33-44.

24. Glenny, R.J.E., and Hopkins, B.E. (1976). Philos. Trans. R. Soc. London A. 282, $105-118$.

25. Gruenling, H., and Hofer, G. (1974). Z. Werkstofftech. 5, 69-72.

26. Hoffman, J., Hofmann, S., and THllmann, L. (1974). Z. Metallkd. 65, $721-726$.

27. Kannappan, A., and Fischmeister, H.F. (1975). In "High Temperature Materials Phenomena" (M. Ti111, ed.) Vol. II, pp. 85-98. Helsinki University of Technology, Esbo, Finland.

28. Karpinos, D.M., et a1. (1972). Fiz. Khim. Obrab. Mater. 6, 107-113.

29. Karpinos, D.M. , et a 1. (1975). Sov. Powder Metal1. Met. Ceram. (Engl. Trans 1.) 14, 447-452.

30. King, G.W., (1972). "Development of Wire-Drawing Processes for RefractoryMetal Fibers." NASA CR-120925.

31. Klypin, B.A., Maslov, A.M., and Maslenkov, S.B., (1977). Met. Sci. Heat Ireat. Met. (Engl. Trans 1. L 19, 343-348.

32. Mazze1, P.J., Vandrunen, G., and Hakim, M.J. (1976). In "Advanced Fabrication Techntques in Powder Metaliurgy and Their Economic Implications" AGARD-CP-200, AGARD, Paris, France.

33. Melnyk, P., and Fleck, J.N. (1979). "Tungsten Wire/FeCrAlY Matrix Turbine Blade Fabrication Study." TRW-ER-8101, TRW Inc., Cleveland, OH. (Also, NASA CR-159788).

34. Mirotvorski1, V.S., and 01'shevsk11, A.A. (1976). Sov. Powder Metal1. Met. Ceram. (Engl. Trans 1.) 15, 534-540.

35. Mirotvorskit, V.S., and 01 'shevsk11, A.A. (1978). Sov. Powder Meta11. Met Ceram. (Engl. Trans 1.) 17, 536-541. 
36. Mirotvorski1, V.S., and 01'shevsk11, A.A. (1979). Met. Sc1. Heat Treat. Met. (Engl. Trans 1.) 21, 826-829.

37. Montelbano, T., et a1. (1968). Trans. Am. Inst. Min. Meta11. Pet. Eng. 242, 1973-1979.

38. Morris, A.W.H., and Burwood-Smith, A. (1970). Fibre Sc1. Technol. 3, 53-78.

39. Morris, A.W.H., and Burwood-Smith, A. (1971). In "High Temperature Turbines" AGARD-CP-73-71, Paper 19. AGARD, Paris, France.

40. Nilsen, N., and Sovik, J.H. (1974). In "Practical Metalitc Composites" pp. 851-854. Institution of Metaliurgists, London.

41. Ohnysty, B., and Stetson, A.R. (1967). "Evaluation of Composite Materials for Gas Turbine Engines." AFML-TR-66-156-Part-2.

42. Petrasek, D.W. (1972). "High-Temperature Strength of Refractory-Metal Wires and Consideration for Composite Applications." NASA TN D-6881.

43. Petrasek, D.W., and Signore111, R.A. (1969) "Stress-Rupture and Tensile Properties of Refractory-Metal Wires at 2000 and $2200{ }^{\circ} \mathrm{F}$ (1093 and $204^{\circ} \mathrm{C}$ )." NASA TN D-5139.

44. Petrasek, D.W., and Signore111, R.A. (1970). "Preliminary Evaluation of Tungsten Alloy Fiber - Nickel-Base Alloy Composites for Turbojet Engine Applications." NASA TN D-5575.

45. Petrasek, D.W., and Signore111, R.A. (1974). "Stress-Rupture Strength and Microstructural Stability of Tungsten-Hafnium-Carbon-Wire Reinforced Superalloy Composites." NASA TN D-7773.

46. Petrasek, D.W., and Weeton, J.W. (1963). "Alloying Effect on Tensile Properties and Micro-Structure of Tungsten-Fiber-Reinforced Composites." NASA TN D-1568.

47. Petrasek, D.W., Signore111, R.A., and Weeton, J.W. (1968). "RefractoryMetal-Fiber-Nickel-Base-Alioy Composites for Use at High Temperatures." NASA TN D-4787.

48. Petrasek, D.W., et al. (1979). "Tungsten Fiber Reinforced FeCrAlY-A First Generation Composite Turbine Blade Material." NASA TM-79094.

49. Sahm, P.R. (1974). In "High-Temperature Materials in Gas Turbines" (P.R. Sahm and M.0. Speidel, eds.) pp. 73-114. Elsevier Scientific, Amsterdam.

50. Severdenko, V.P., Matusevich, A.S., and Piskarev, A.E. (1974). Sov. Powder Meta 11. Met. Ceram. (Engl. Trans 1.) 13, 476-479.

51. Signore111, R.A. (1972). "Review of Status and Potential of Tungsten Wire: Superalloy Composites for Advanced Gas Turbine Engine Blades." NASA TM X-2599. 
52. Signorell1, R.A., Johnston, J.R., and Weeton, J.W. (1956). "Preliminary Investigation of Guy Alloy as a Turbojet-Engine Bucket Material for Use at $1650^{\circ} \mathrm{F}$." NACA RM-E56I19.

53. Speidel, M.0. (1974). In "High-Temperature Materials in Gas Turbines" (P.R. Sahm and M.O. Speidel, eds.) pp. 207-255. Elsevier Scientific, Amsterdam.

54. Stetson, A.R., et al. (1966). "Evaluation of Composite Materials for Gas Turbine Engines." AFML-TR-66-156-Part-1, Air Force Materials Lab., Wright-Patterson AFB, OH.

55. Waters, W.J., Signorelli, R.A., and Johnston, J.R., (1959). "Performance of Two Boron-Modified S-816 Alloys in a Turbojet Engine Operated at $1650{ }^{\circ} \mathrm{F} . "$ NASA Memo 3-3-59E.

56. Westfa11, L.J. (1985). "Tungsten Fiber Reinforced Superalloy Eomposite Monolayer Fabrication by an ARC-SPRAY Process." NASA TM-86917.

57. Winsa, E.A., and Petrasek, D.W. (1973). "Factors Affecting Miniature Izod Impact Strength of Tungsten-Fiber-Metal-Matrix Composites." NASA TN D-7393.

58. Winsa, E.A., Westfall, L.J., and Petrasek, D.W. (1978). In "ICCM/2" (B.R. Norton et al, eds.) pp. 840-857. Metallurgical Society of AIME, Philadelphia.

59. Wukusick, C.S. (1966). "The Physical Metallurgy and Oxidation Behavior of Fe-Cr-Al-Y Alloys." GEMP-414, General Electric Co., Cincinnat1, OH. 
TABLE I. - CHEMICAL COMPOSITION OF WIRE MATERIALS $[42,43]$

\begin{tabular}{|c|c|c|c|c|c|c|c|c|c|c|}
\hline \multirow[t]{2}{*}{ Material } & \multicolumn{10}{|c|}{ Weight percent of component } \\
\hline & $W$ & $\mathrm{Ta}$ & Mo & $\mathrm{Nb}$ & $\operatorname{Re}$ & $\mathrm{Ti}$ & $\mathrm{Zr}$ & $\mathrm{Hf}$ & $\mathrm{ThO}_{2}$ & c \\
\hline \multirow{2}{*}{\multicolumn{11}{|c|}{ Tungst }} \\
\hline $218 \mathrm{CS}$ & 99.9 & $-\infty$ & $\ldots$ & -- & ----- & & & & & -- - - \\
\hline $\mathrm{W}-1 \mathrm{ThO}_{2}$ & bal & ---- & -- & --- & --- & $\ldots$ & --- & ---- & 0.95 & ---- \\
\hline $\mathrm{W}-2 \mathrm{ThO}_{2}$ & & --- & - & -- & ---- & $-\cdots$ & -..- & --- & 1.6 & $-\cdots$ \\
\hline$W-3 \operatorname{Re}$ & & $--\infty$ & --- & --- & 2.79 & ---- & ---- & ---- & --- & --- \\
\hline $\mathrm{W}-5 \mathrm{Re}-2 \mathrm{ThO}_{2}$ & & --- & -- & -- & $\begin{array}{r}4.89 \\
22.54\end{array}$ & -- & ---- & --- & 1.78 & $-\cdots$ \\
\hline $\begin{array}{l}W-24 R e-2 T h O_{2} \\
W-H f-C\end{array}$ & & --- & -- & -- & 22.54 & $\ldots$ & $-\cdots$ & $\overline{0.37}$ & 1.7 & 0.030 \\
\hline W-Re-Hf-C & & -..-- & - & --- & 4.1 & --- & --- & .38 & --- & .021 \\
\hline Tantalum alloys & & & & & & & & & & \\
\hline $\begin{array}{l}\text { ASTAR } 811 \mathrm{C} \\
\text { Mol ybdenum alloys }\end{array}$ & 8.2 & bal & -- & --- & ---- & 1.13 & ---- & .91 & -- & .027 \\
\hline TZM & ---- & ---- & bal & $-\cdots$ & $-\ldots--$ & .45 & 0.085 & --- & --- & .031 \\
\hline TZC & --- & ----- & bal & - & ---- & 1.18 & .27 & ---- & --- & .12 \\
\hline FS85 & 10.44 & 27.95 & -- & bal & ----- & --- & .85 & -- & ---- & .031 \\
\hline AS30 & 20 & $-\cdots$ & -- & bal & --- & --- & & -10 & -- & ---- \\
\hline & & & & & & & & & & \\
\hline
\end{tabular}


TABLE II. - REPRESENTATIVE PROPERTIES OF REFRACTORY-ALLOY WIRES $[42,43]$

\begin{tabular}{|c|c|c|c|c|c|c|c|}
\hline \multirow[t]{2}{*}{ Alloys } & \multirow[t]{2}{*}{$\begin{array}{l}\text { Density } \\
\mathrm{gm} / \mathrm{cm}^{3}\end{array}$} & \multirow[t]{2}{*}{$\begin{array}{c}\text { Wire } \\
\text { diameter, } \\
\mathbf{m m}\end{array}$} & \multicolumn{2}{|c|}{$\begin{array}{l}\text { Ultimate } \\
\text { tensile } \\
\text { strength }\end{array}$} & \multicolumn{2}{|c|}{$\begin{array}{l}\text { Stress for } \\
100-h r \\
\text { rupture }\end{array}$} & \multirow{2}{*}{$\begin{array}{l}\text { Stress/density } \\
\text { for } 100-\mathrm{hr} \\
\text { rupture, } \\
\text { cmx10 }\end{array}$} \\
\hline & & & ksi & $M N / m^{2}$ & $k s \mathbf{i}$ & $\mathrm{MN} / \mathrm{m}^{2}$ & \\
\hline \multicolumn{8}{|c|}{ A. $1093^{\circ} \mathrm{C}\left(2000^{\circ} \mathrm{F}\right)$ Data } \\
\hline $\begin{array}{l}\text { Tungsten alloys } \\
218 \mathrm{CS} \\
\text { W-1Th0 } \\
\text { W-2Th02 } \\
\text { W-3Re } \\
\text { W-5Re-2ThO }{ }_{2} \\
\text { W-24Re-2Th0 } \\
\text { W-Hf-C } \\
\text { W-Re-Hf-C } \\
\text { Tantalum alloys } \\
\text { ASTAR } 811 \mathrm{C} \\
\text { Molybdenum alloys } \\
\text { TZM } \\
\text { TZC } \\
\text { Niobium alloys } \\
\text { FS85 } \\
\text { AS30 } \\
\text { B88 }\end{array}$ & $\begin{array}{l}19.1 \\
19.1 \\
18.9 \\
19.4 \\
19.1 \\
19.4 \\
19.4 \\
19.4 \\
16.9\end{array}$ & $\begin{array}{r}0.20 \\
.20 \\
.38 \\
.20 \\
.20 \\
.20 \\
.38 \\
.38 \\
.51\end{array}$ & $\begin{array}{l}126 \\
142 \\
173 \\
214 \\
176 \\
211 \\
207 \\
314\end{array}$ & $\begin{array}{r}869 \\
979 \\
1193 \\
1475 \\
1213 \\
1455 \\
1427 \\
2165 \\
\\
745\end{array}$ & $\begin{array}{r}63 \\
77 \\
95 \\
69 \\
70 \\
50 \\
161 \\
205\end{array}$ & $\begin{array}{r}434 \\
531 \\
655 \\
476 \\
483 \\
345 \\
1110 \\
1413 \\
579\end{array}$ & $\begin{array}{l}234 \\
282 \\
356 \\
249 \\
254 \\
183 \\
584 \\
744\end{array}$ \\
\hline
\end{tabular}

\begin{tabular}{|c|c|c|c|c|c|c|c|}
\hline \multicolumn{8}{|c|}{ B. $1204^{\circ} \mathrm{C}\left(2200^{\circ} \mathrm{F}\right)$ Data } \\
\hline $\begin{array}{l}\text { Tungsten alloys } \\
\text { 218CS } \\
\text { W-1ThO } \\
\text { W-2ThO2 } \\
\text { W-3Re } \\
\text { W-5Re-2Th02 } \\
\text { W-24Re-2Th0 } 2 \\
\text { W-Hf-C } \\
\text { W-Re-Hf-C } \\
\text { Tantalum alloys } \\
\text { ASTAR } 811 C \\
\text { Molybdenum alloys } \\
\text { TZM } \\
\text { TZC } \\
\text { Niobium alloys } \\
\text { FS85 } \\
\text { AS30 } \\
\text { B88 }\end{array}$ & $\begin{array}{l}19.1 \\
19.1 \\
18.9 \\
19.4 \\
19.1 \\
19.4 \\
19.4 \\
19.4\end{array}$ & $\begin{array}{r}0.20 \\
.20 \\
.38 \\
.20 \\
.20 \\
.20 \\
.38 \\
.38 \\
.51\end{array}$ & $\begin{array}{l}108 \\
122 \\
150 \\
157 \\
148 \\
147 \\
201 \\
281 \\
71\end{array}$ & $\begin{array}{r}745 \\
841 \\
1034 \\
1082 \\
1020 \\
1014 \\
1386 \\
1937\end{array}$ & $\begin{array}{r}46 \\
54 \\
70 \\
46 \\
44 \\
28 \\
111 \\
132 \\
38\end{array}$ & $\begin{array}{l}317 \\
372 \\
483 \\
317 \\
303 \\
193 \\
765 \\
910 \\
\\
262\end{array}$ & $\begin{array}{l}170 \\
198 \\
257 \\
168 \\
160 \\
102 \\
404 \\
480 \\
\\
157\end{array}$ \\
\hline
\end{tabular}

TABLE III. - COMPARISON OF FIBER-MATRIX REACTIONS FOR VARIOUS MATRIX MATERIALS [36]

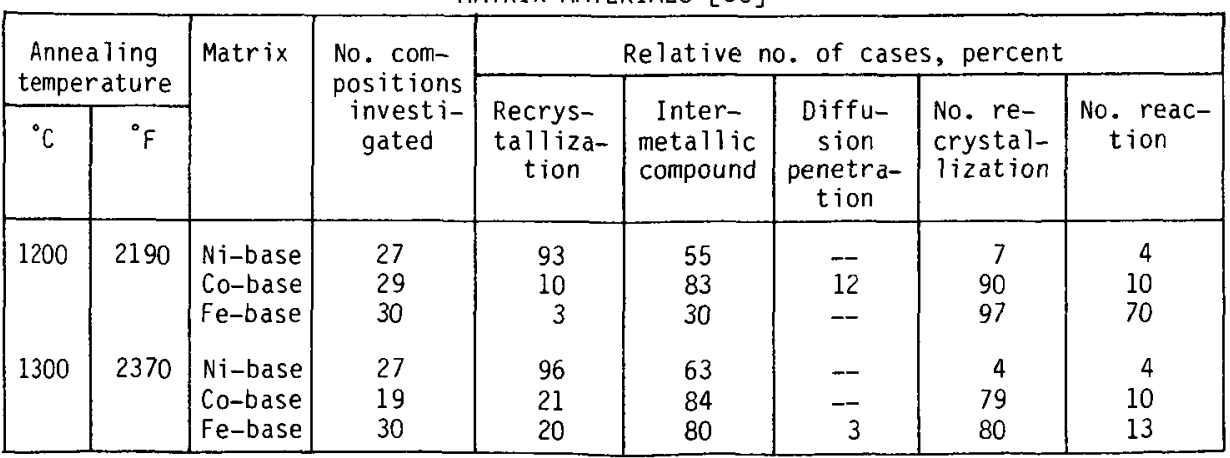


TABLE IV. - PARABOLIC RATE CONSTANTS

$\left(\times 10^{-12} \mathrm{~cm}^{2} / \mathrm{s}\right)$ FOR VARIOUS METAL

W-FIBER/MATR I $X$ COMPOSITES ANNEALED

AT $1093{ }^{\circ} \mathrm{C} . \quad K_{r z}(T), K_{f}(T)$, AND

$K_{m}(T)$ DENOTE THE OVERALL REACTION

ZONE KINETICS, THE FIBER COMPONENT

OF REACTION ZONE GROWTH, AND THE

MATRIX COMPONENT OF REACTION

ZONE GROWTH, RESPECTIVELY

$[11,12]$

\begin{tabular}{|l|c|c|c|}
\hline \multicolumn{1}{|c|}{ Matrix } & $\mathrm{K}_{r z}(\mathrm{~T})$ & $\mathrm{K}_{\mathrm{f}}(\mathrm{T})$ & $\mathrm{K}_{\mathrm{m}}(\mathrm{T})$ \\
\hline FeCrAly & 4.1 & 2.9 & 0.1 \\
SS 316 & 4.9 & 1.7 & .8 \\
Incoloy 907 & 2.8 & 1 & .3 \\
Incoloy 903 & 1.35 & .5 & .2 \\
Waspaloy & .5 & .2 & .04 \\
\hline
\end{tabular}

annealed at $1100{ }^{\circ} \mathrm{C}$.

TABLE V. - RUPTURE STRENGTHS AND COMPOSITIONS FOR COMPOSITIES AND SUPERALLOYS

\begin{tabular}{|c|c|c|c|c|c|c|c|c|c|c|c|}
\hline \multicolumn{12}{|c|}{ A. $100 \mathrm{hr}$ rupture strength at $1100^{\circ} \mathrm{C}\left(2010^{\circ} \mathrm{F}\right)$ for composities and superalloys } \\
\hline \multirow[t]{3}{*}{ Ref. } & \multirow[t]{3}{*}{ Alloy } & \multirow[t]{3}{*}{ Wire } & \multicolumn{2}{|c|}{ Wire diam } & \multirow[t]{3}{*}{ Vol. \% } & \multicolumn{2}{|c|}{ Density } & \multicolumn{2}{|c|}{$100 \mathrm{hr}$ rupture strength } & \multirow{2}{*}{\multicolumn{2}{|c|}{$\begin{array}{l}\text { Stress-density for } \\
100 \mathrm{hr} \text { rupture }\end{array}$}} \\
\hline & & & \multirow{2}{*}{$\mathrm{mm}$} & \multirow{2}{*}{ in. } & & \multirow{2}{*}{$\mathrm{gm} / \mathrm{cc}$} & \multirow{2}{*}{$\mathrm{ib} / \mathrm{in}^{3}$} & \multirow{2}{*}{$\mathrm{MN} / \mathrm{m}^{2}$} & \multirow{2}{*}{$k s i$} & & \\
\hline & & & & & & & & & & m & in. \\
\hline 13 & Zh56 & $\begin{array}{l}\text { VRN } \\
\text { tungsten }\end{array}$ & $0.3-0.5$ & $0.012-0.020$ & 40 & 12.5 & 0.45 & 138 & 20 & 1125 & 44300 \\
\hline $\begin{array}{l}15 \\
15\end{array}$ & EPD-16 & tungsten & $---1-25$ & 0.010 & $\overline{40}$ & $\begin{array}{r}8.3 \\
12.7\end{array}$ & $\begin{array}{l}0.3 \\
.46\end{array}$ & $\begin{array}{r}51 \\
131\end{array}$ & 19.4 & $\begin{array}{r}635 \\
1040\end{array}$ & $\begin{array}{ll}25 & 000 \\
41000\end{array}$ \\
\hline $\begin{array}{l}38 \\
38 \\
\end{array}$ & Nimocast $713 \mathrm{C}$ & tungsten & $----\overline{1.27}$ & 0.050 & $\overline{20}$ & $\begin{array}{r}8.0 \\
10.3\end{array}$ & $\begin{array}{r}0.29 \\
.37\end{array}$ & $\begin{array}{l}48 \\
93\end{array}$ & $\begin{array}{c}7 \\
13.5\end{array}$ & $\begin{array}{l}613 \\
927\end{array}$ & $\begin{array}{ll}24 & 000 \\
36 & 500\end{array}$ \\
\hline $\begin{array}{l}1 \\
1\end{array}$ & MARM $322 E$ & $\mathrm{~W}-2 \% \mathrm{ThO}_{2}$ & $\overline{0.08}$ & 0.003 & $\overline{40}$ & $-\infty$ & --- & $\begin{array}{r}48 \\
207\end{array}$ & $\begin{array}{r}7 \\
30\end{array}$ & ---- & --- \\
\hline $\begin{array}{l}47 \\
47\end{array}$ & $\mathrm{Ni}, \mathrm{Cr}, \mathrm{W}, \mathrm{Al}, \mathrm{Ti}$ & $\begin{array}{l}218 \mathrm{CS} \\
\text { (tungsten) }\end{array}$ & 0.38 & 0.015 & $\overline{40}$ & $\begin{array}{l}9.15 \\
13.3\end{array}$ & $\begin{array}{r}0.33 \\
.48\end{array}$ & $\begin{array}{r}23 \\
138\end{array}$ & $20^{3.3}$ & $\begin{array}{r}254 \\
1058\end{array}$ & $\begin{array}{ll}10 & 000 \\
41 & 700\end{array}$ \\
\hline $\begin{array}{l}44 \\
45 \\
\end{array}$ & & $\begin{array}{l}\mathrm{W}-2 \% \mathrm{ThO}_{2} \\
\mathrm{~W}-\mathrm{Hf}-\mathrm{C}\end{array}$ & $\begin{array}{r}0.38 \\
.38 \\
\end{array}$ & $\begin{array}{r}0.015 \\
.015\end{array}$ & $\begin{array}{l}40 \\
40\end{array}$ & $\begin{array}{l}13.0 \\
13.3\end{array}$ & $\begin{array}{r}0.47 \\
.48\end{array}$ & $\begin{array}{l}193 \\
324\end{array}$ & $\begin{array}{l}28 \\
47\end{array}$ & $\begin{array}{l}1513 \\
2491\end{array}$ & $\begin{array}{ll}59 & 600 \\
98 & 000\end{array}$ \\
\hline 7 & FeCrAtY & $\mathrm{W}-1 \% \mathrm{ThO}_{2}$ & 0.38 & 0.015 & 56 & 12.5 & 0.45 & \multicolumn{2}{|c|}{$\begin{array}{l}831 \mathrm{hr} \text { rupture } \\
\text { strength-242 } \mathrm{MN} / \mathrm{m}^{2}(35 \mathrm{ksi})\end{array}$} & 1957 & 77000 \\
\hline 20 & FeCrAlY & $W-H f-C$ & 0.38 & 0.015 & 35 & 11.3 & 0.41 & 242 & 35 & 2147 & 84500 \\
\hline \multicolumn{12}{|c|}{ B. Nominal composition of matrix alloys (weight $\%$ ) } \\
\hline & $\begin{array}{l}\text { ZhS6 } \\
\text { EPD-16 } \\
\text { Nimocast } 713 \mathrm{C} \\
\text { MARM } 322 \mathrm{E} \\
\text { Ni,Cr,W,Ti,Al } \\
\text { FeCrAiY }\end{array}$ & \multicolumn{10}{|c|}{$\begin{array}{l}\mathrm{Ni}-12.5 \mathrm{Cr}-4.8 \mathrm{Mo}-7 \mathrm{~W}-2.5 \mathrm{~T} i-5 \mathrm{Al} \\
\mathrm{Ni}-6 \mathrm{~A}-6 \mathrm{Cr}-2 \mathrm{Mo}-11 \mathrm{~W}-1.5 \mathrm{Nb} \\
\mathrm{Ni}-12.5 \mathrm{Cr}-6 \mathrm{Al}-1 \mathrm{~T} \mathrm{i}-4 \mathrm{Mo}-2 \mathrm{Nb}-2.5 \mathrm{Fe} \\
\mathrm{Co}-21.5 \mathrm{Cr}-25 \mathrm{~W}-10 \mathrm{~N} \mathrm{i}-0.8 \mathrm{~T} \mathrm{i}-3.5 \mathrm{Ta} \\
\mathrm{Ni}-15 \mathrm{Cr}-25 \mathrm{~W}-2 \mathrm{Ti}-2 \mathrm{Al} \\
\mathrm{Fe}-24 \mathrm{Cr}-5 \mathrm{Al}-1 \mathrm{Y}\end{array}$} \\
\hline
\end{tabular}


TABLE VI. - THERMAL CYCLING DATA FOR TUNGSTEN/SUPERALLOY COMPOSITES

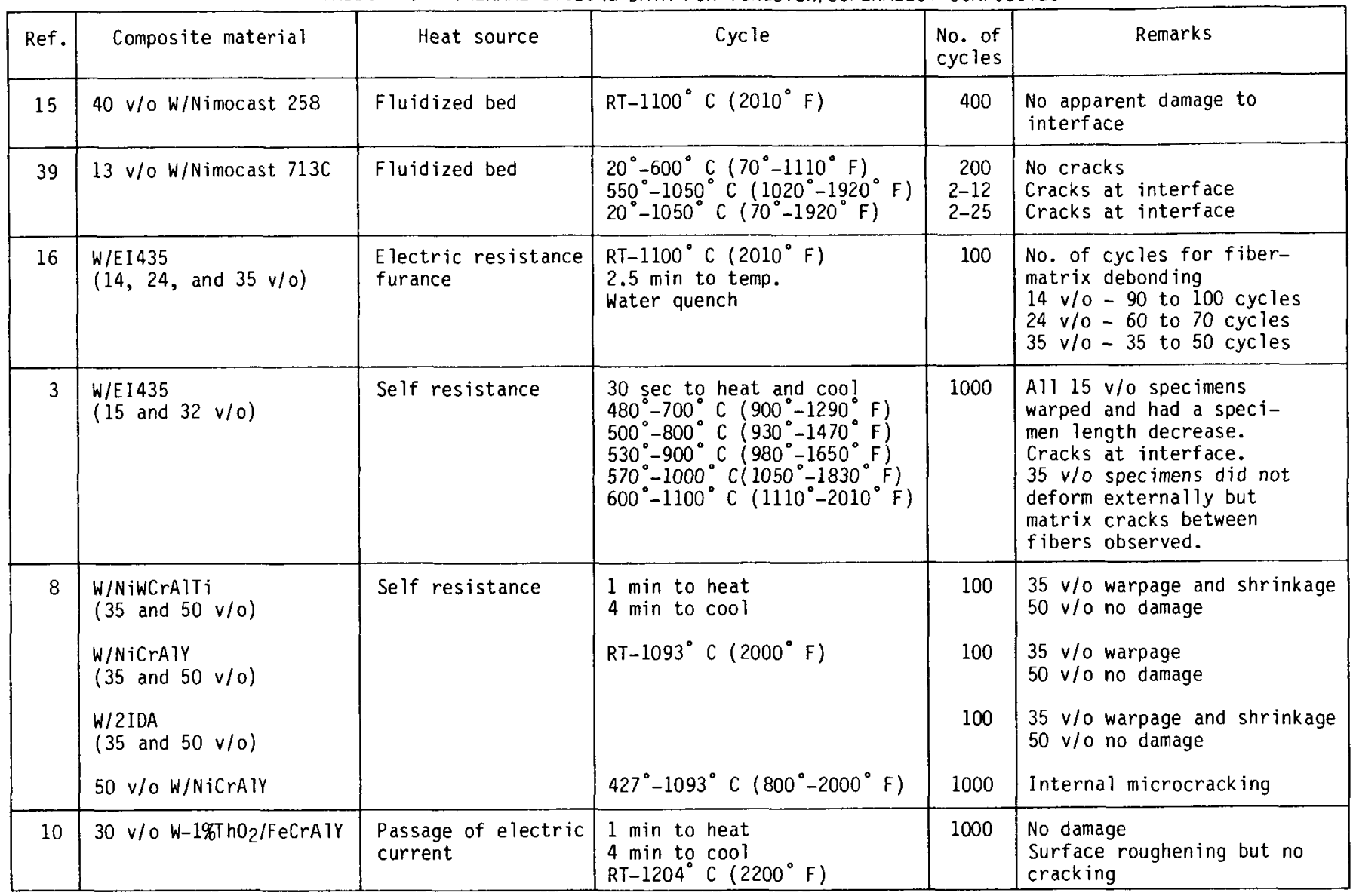




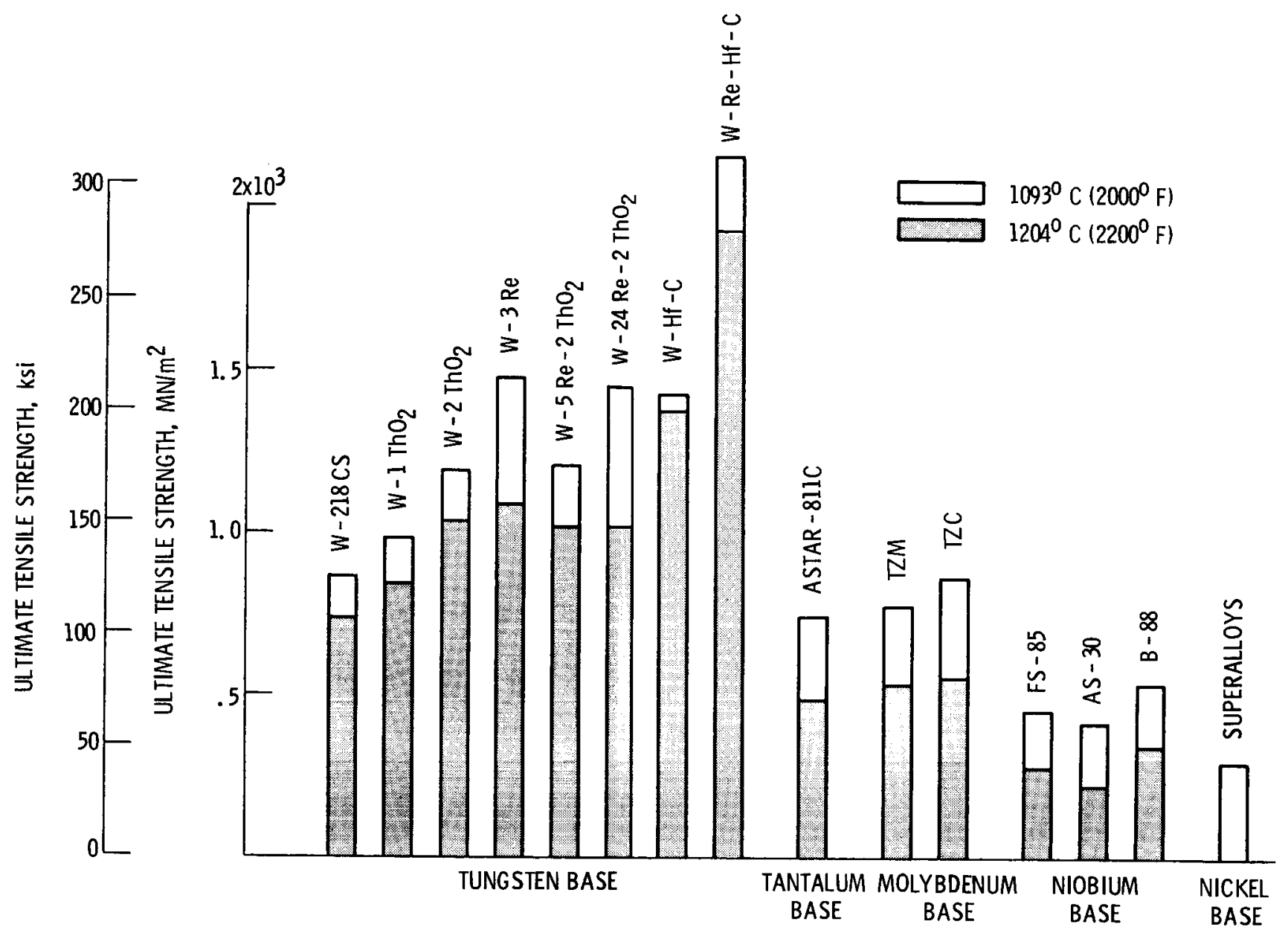

Figure 1. - Ultimate tensile strength for refractory metal wires and superalloys. [42, 43] 


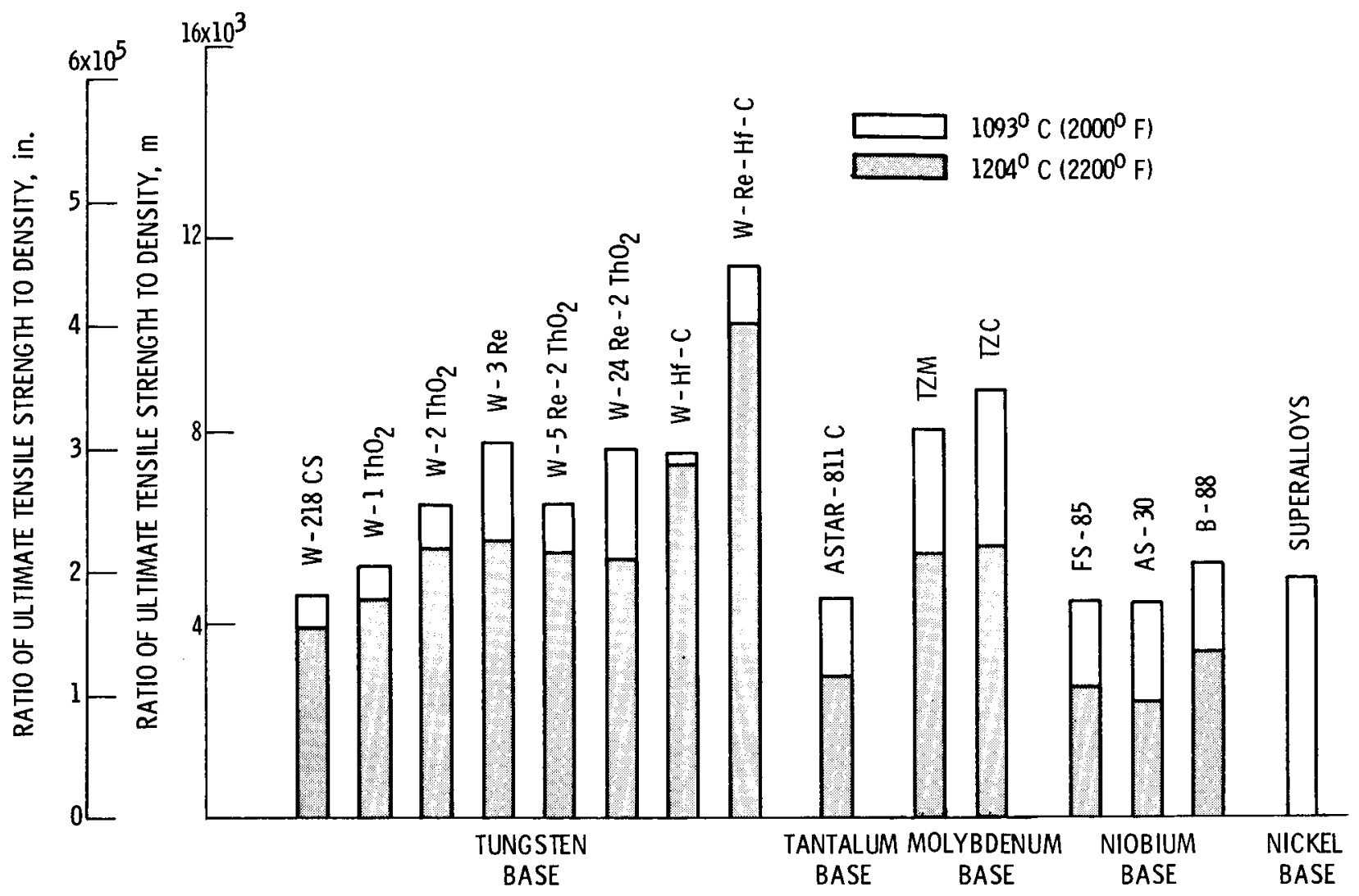

Figure 2. - Ratio of ultimate tensile strength to density for refractory metal wires and superalloys. [42, 43]

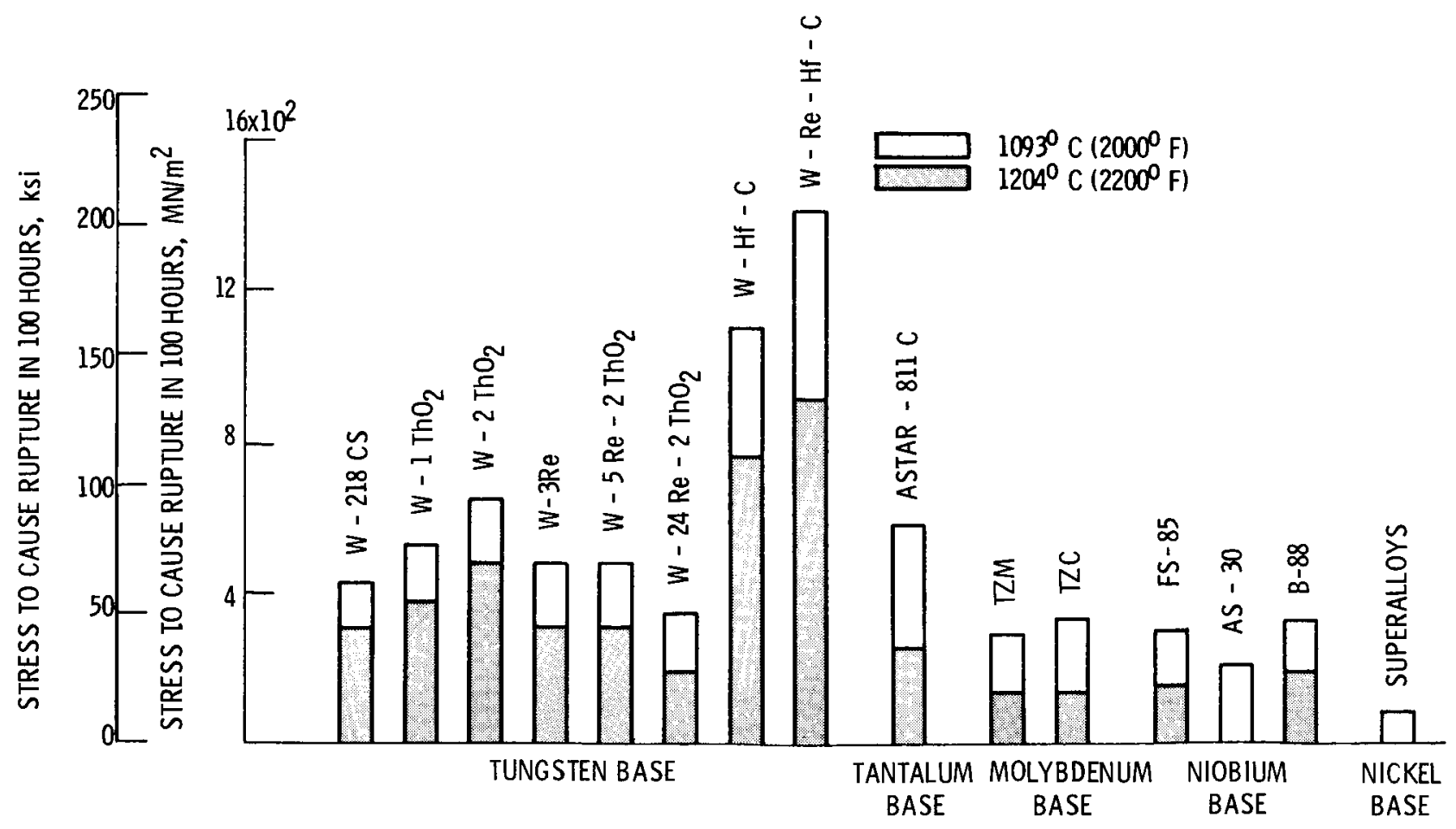

Figure 3. - Stress to cause rupture in 100 hours for refractory metal wires and superalloys. [42, 43] 


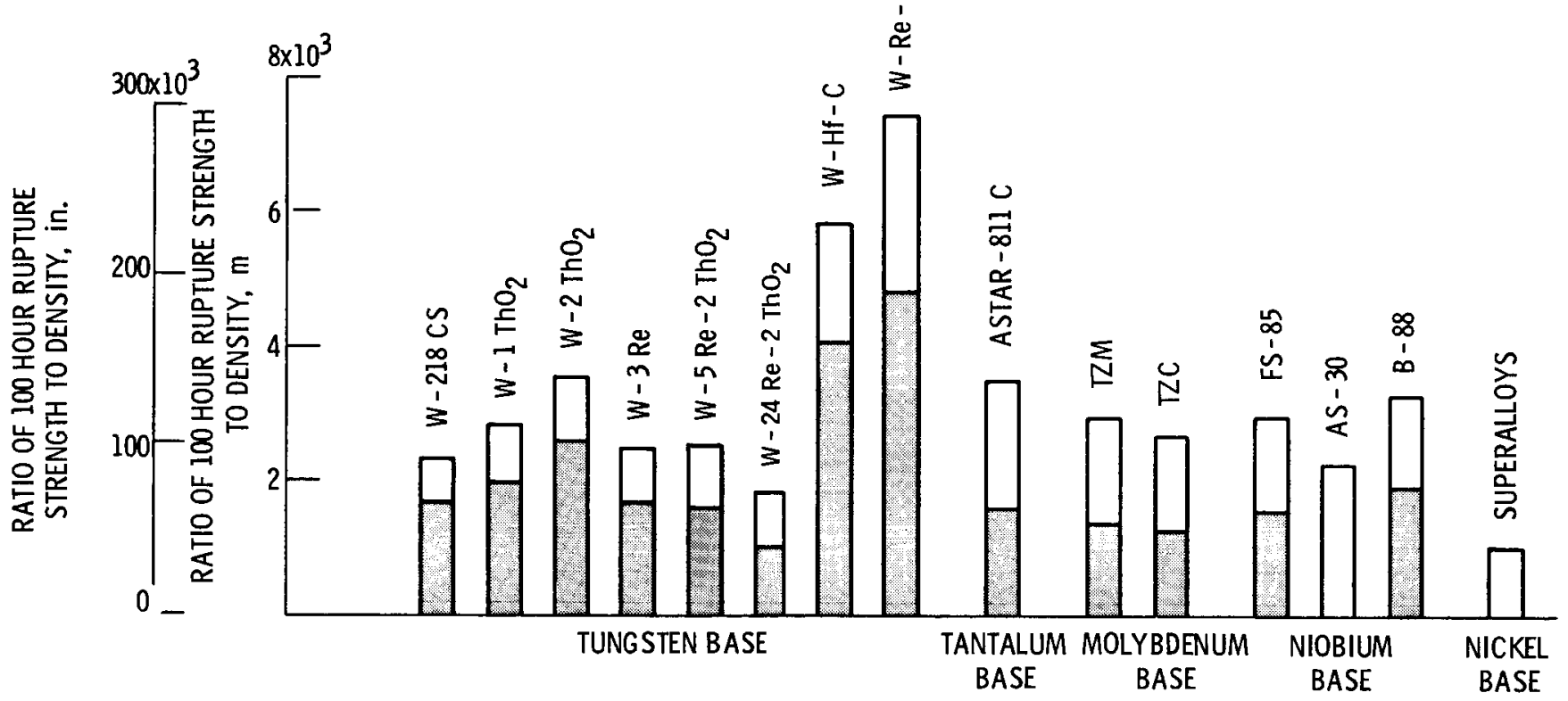

Figure 4. - Ratio of 100 hour rupture strength to density for refractory metal wires and superalloys. [42, 43] 
OR POOR QuALTY
Ont

of. Po:
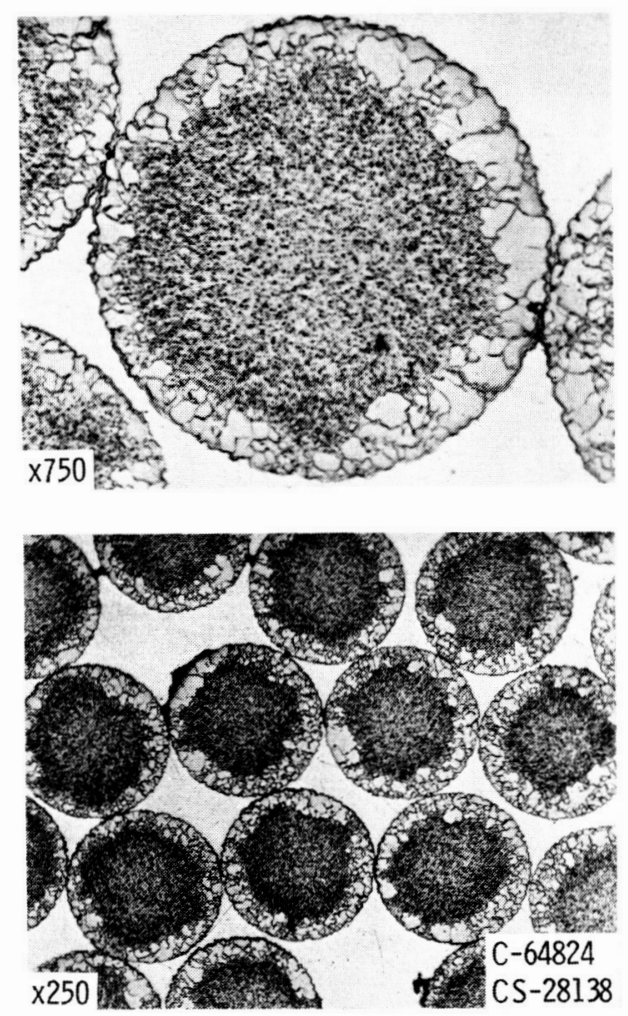

Figure 5. - Recrystallization of tungsten fibers in a copper plus 10 percent nickel matrix. [47] 


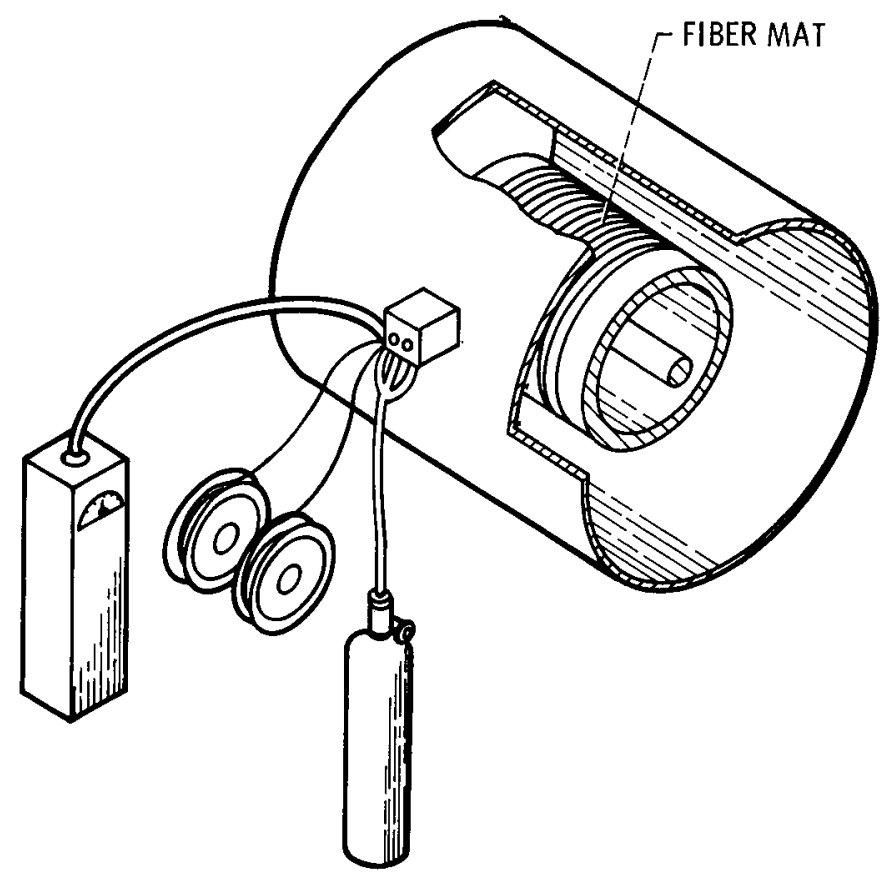

(a) Overall view.

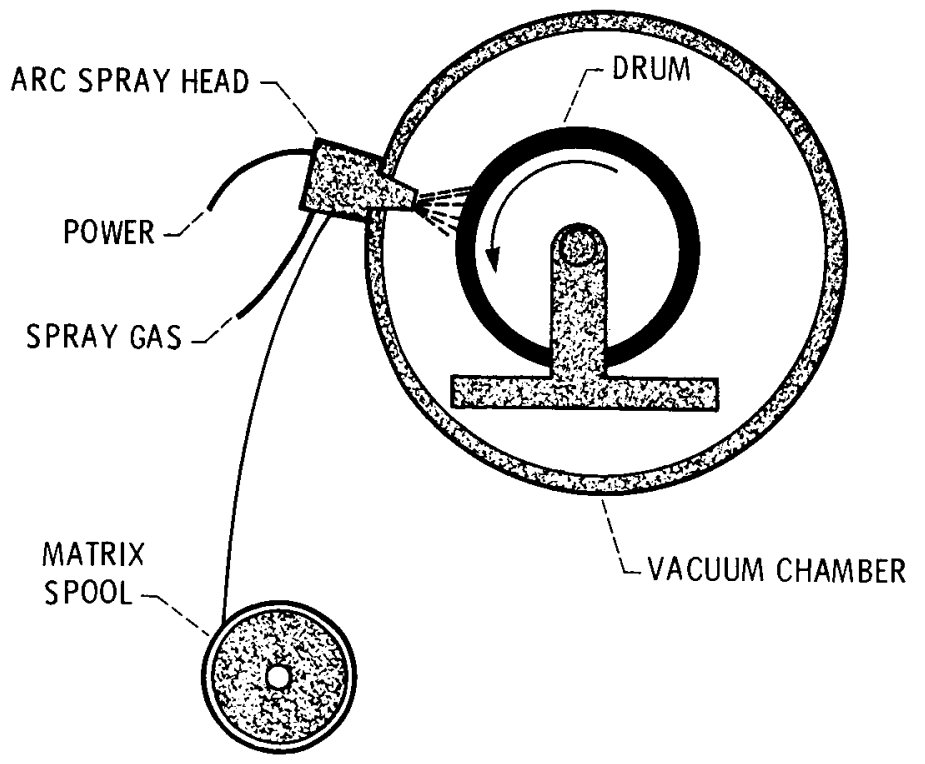

(b) Schematic of arc spray process.

Figure 6. -Schematic view of arc spray monotape fabrication unit. 


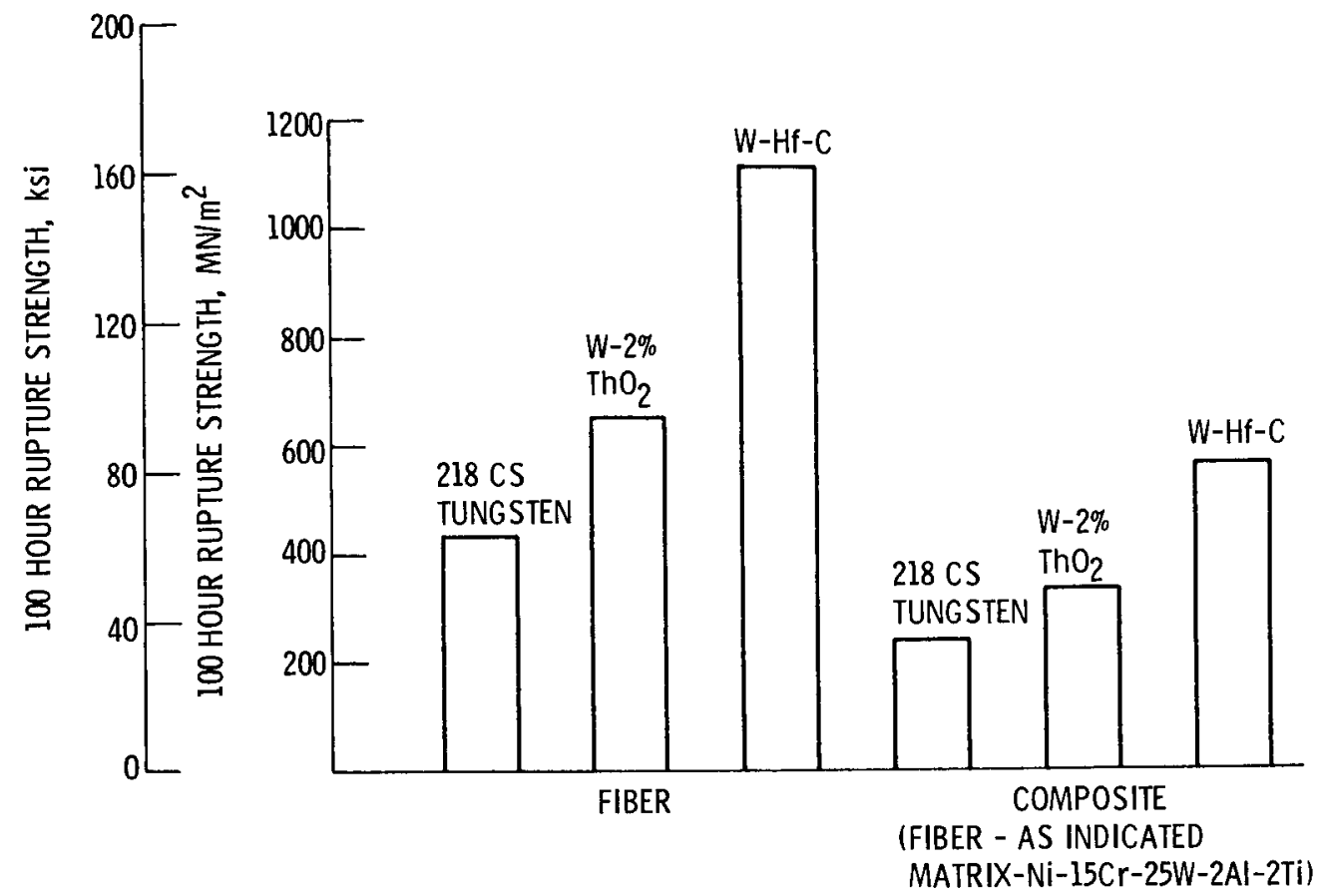

Figure 7. - Comparison of 100 hour rupture strength at $1093^{\circ} \mathrm{C}\left(2000^{\circ} \mathrm{F}\right)$ for fibers and 70 volume percent fiber composites. [44, 45, 47]

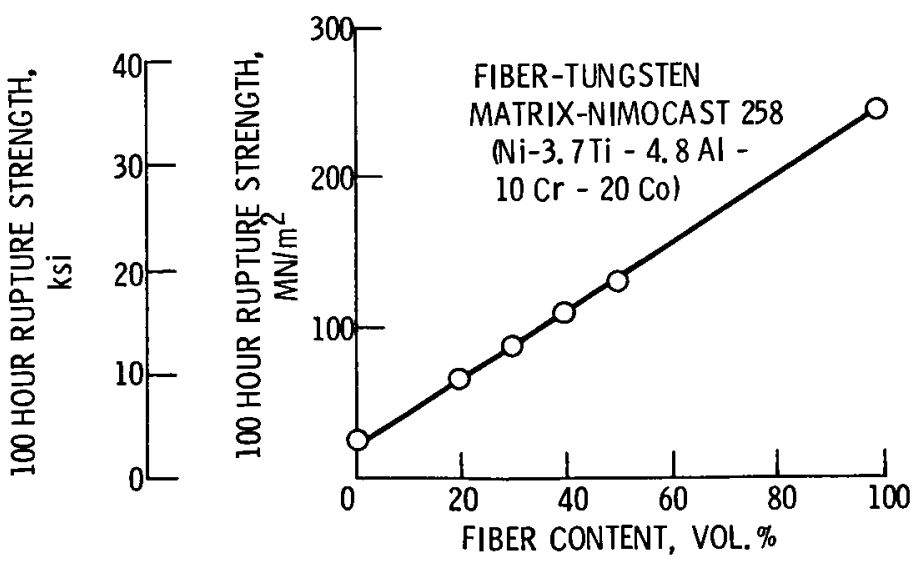

Figure 8. - Effect of fiber content on 100 hour composite rupture strength at $1100^{\circ} \mathrm{C}\left(2010^{\circ} \mathrm{F}\right)$. [15] 


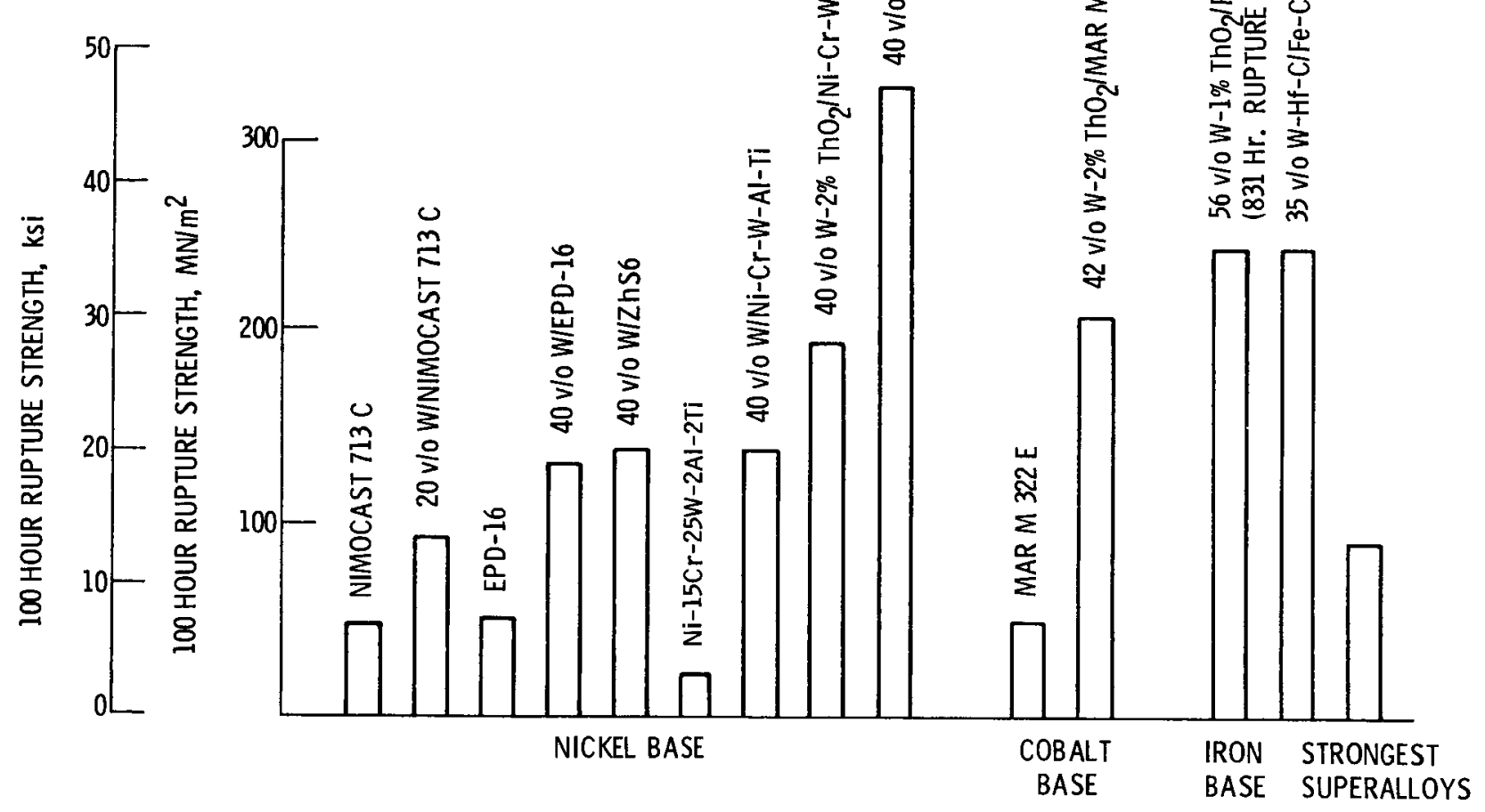

Figure 9. - Comparison of 100 hour rupture strength at $1093^{\circ} \mathrm{C}\left(2000^{\circ} \mathrm{F}\right)$ for composites and superalloys. 


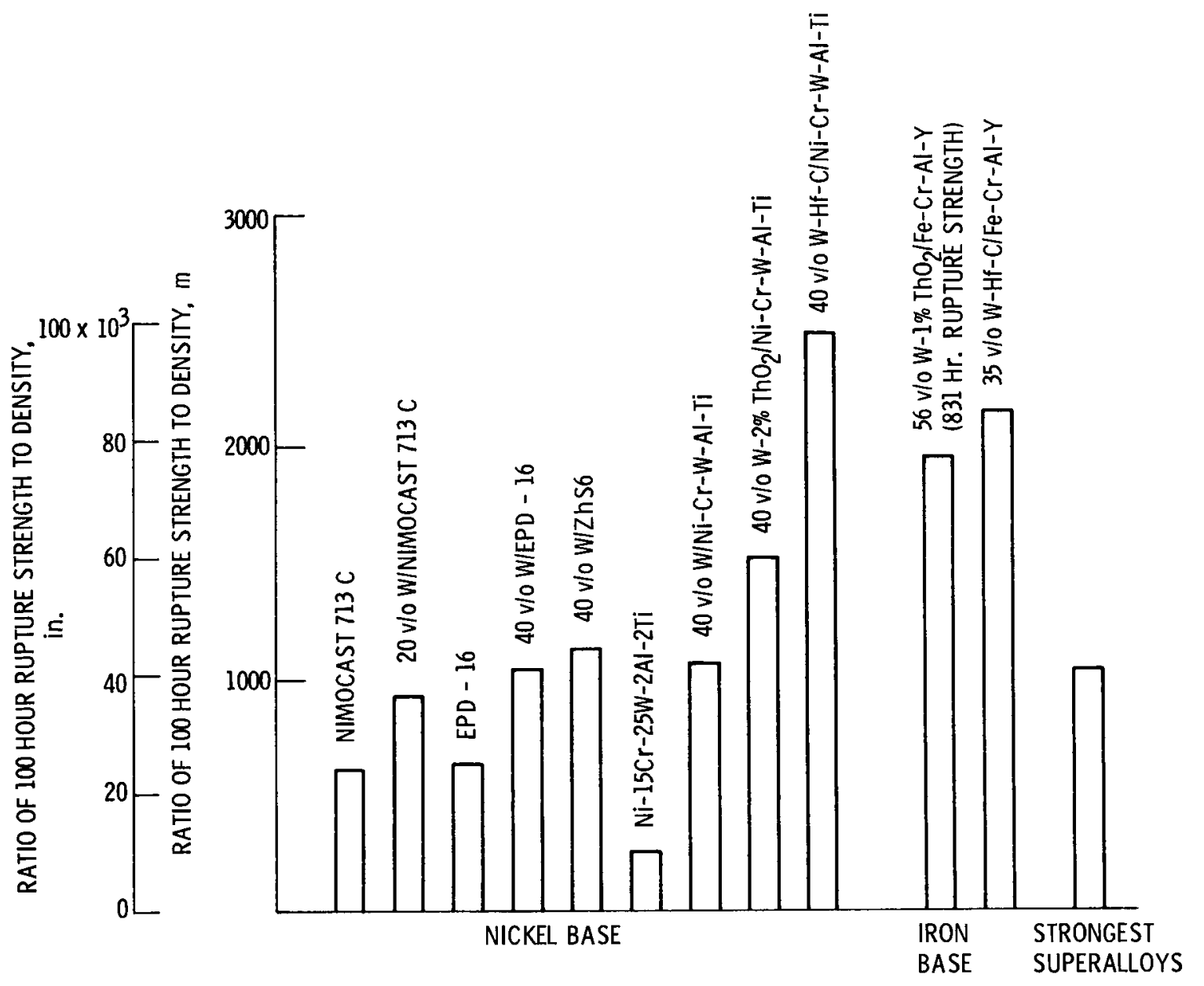

Figure 10. - Comparison of the ratio of 100 hour rupture strength to density for composites and superalloys at $1093^{\circ} \mathrm{C}\left(2000^{\circ} \mathrm{F}\right)$.

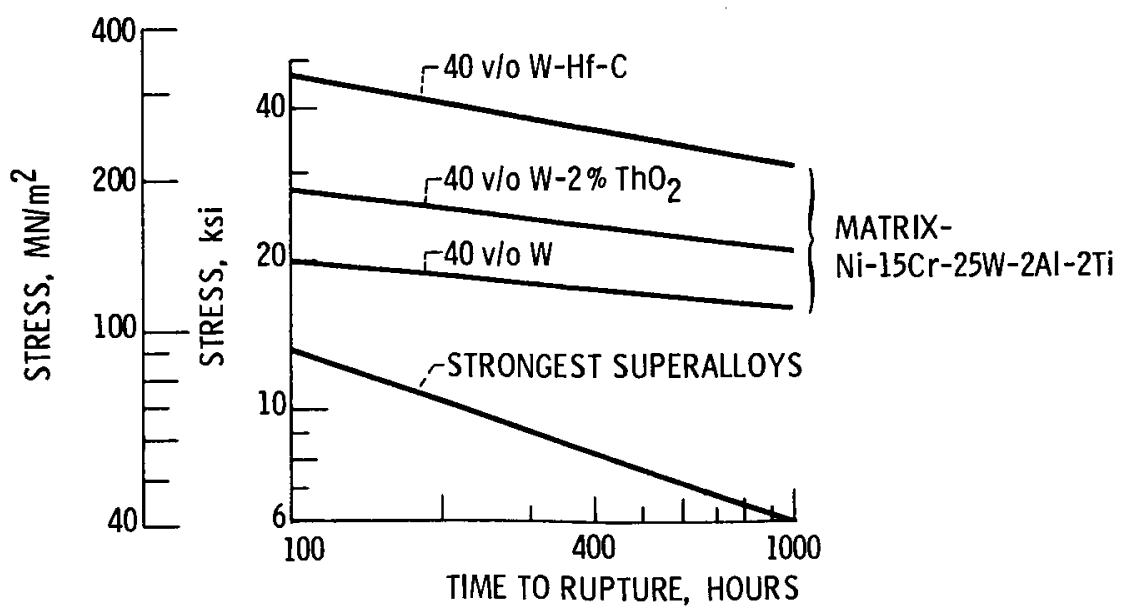

Figure 11. - Stress versus time to rupture comparison for composites and superalloys at $1093^{\circ} \mathrm{C}\left(2000^{\circ} \mathrm{F}\right)$. 


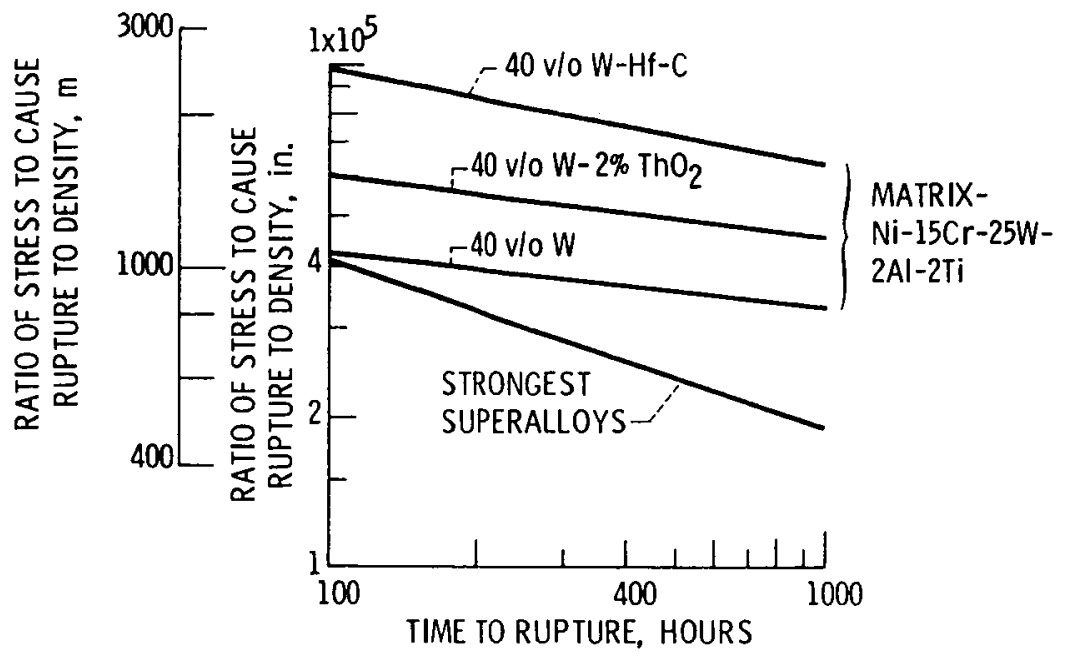

Figure 12. - Stress (to cause rupture) to density ratio for composites and superalloys at $1093^{\circ} \mathrm{C}\left(2000^{\circ} \mathrm{F}\right)$.
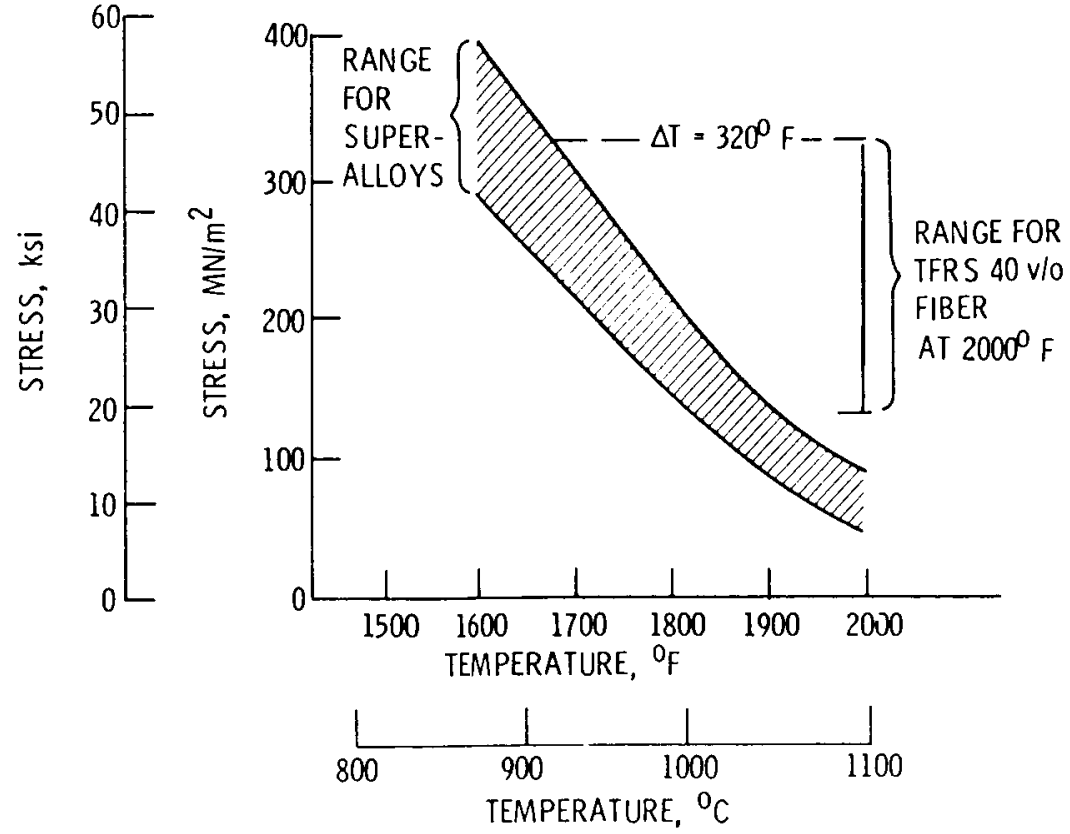

Figure 13. - Comparison of 100 hour rupture strength for TFRS and superalloys. 


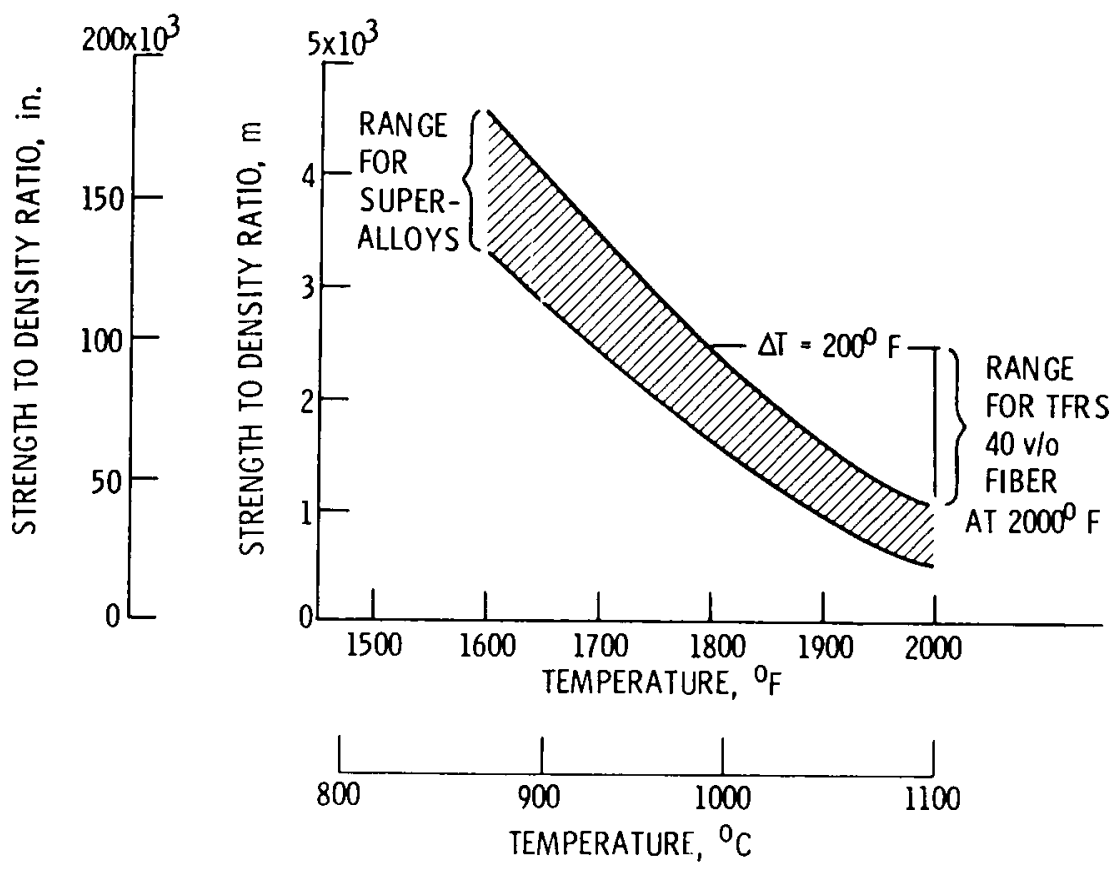

Figure 14. - Comparison of the ratio of 100 hour rupture strength to density for TFRS and superalloys.

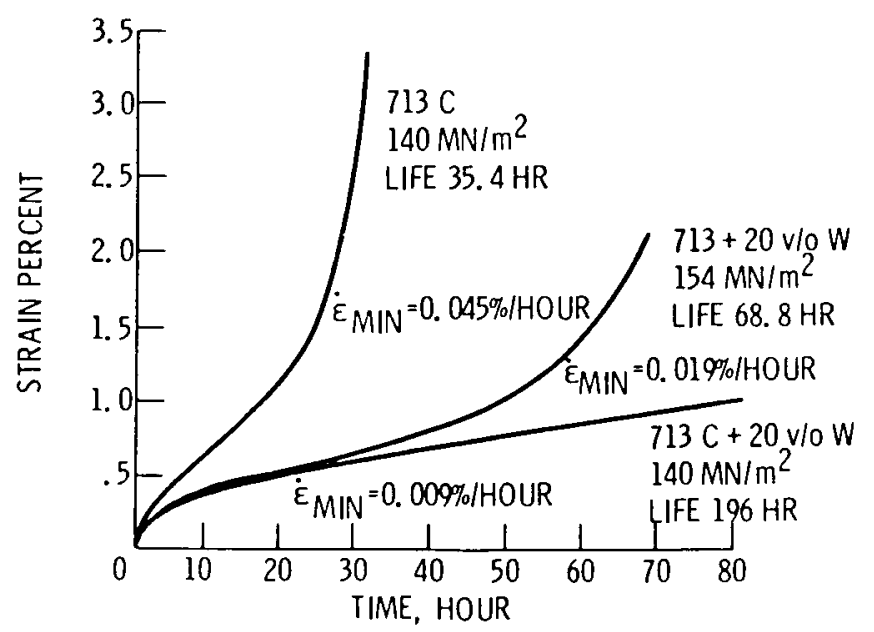

Figure 15. - Comparison of typical creep behaviour of Nimocast $713 \mathrm{C}$ with and without tung sten reinforcement at $1100^{\circ} \mathrm{C}\left(2010^{\circ} \mathrm{F}\right)$. [38] 


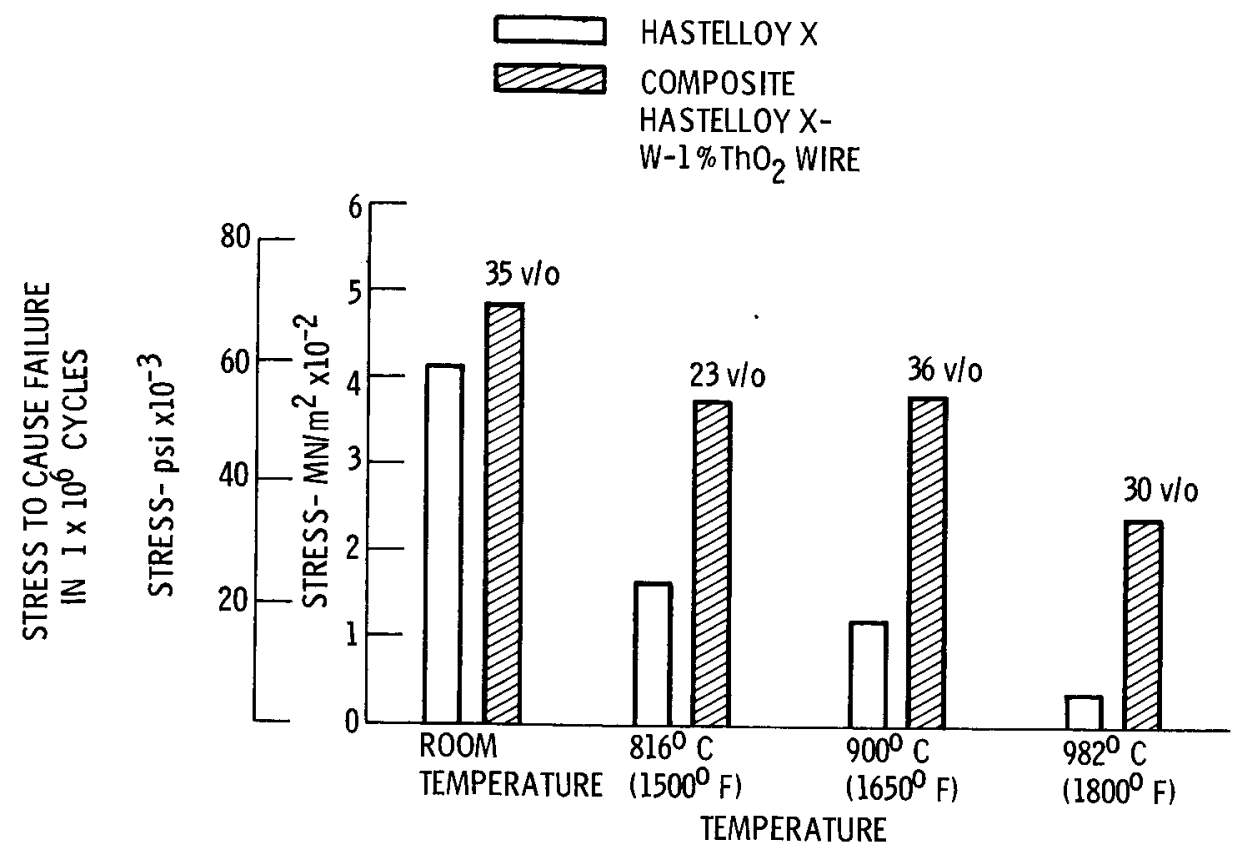

Figure 16. - Stress for failure in $1 \times 10^{6}$ cycles for Hastelloy $X$ and composite.

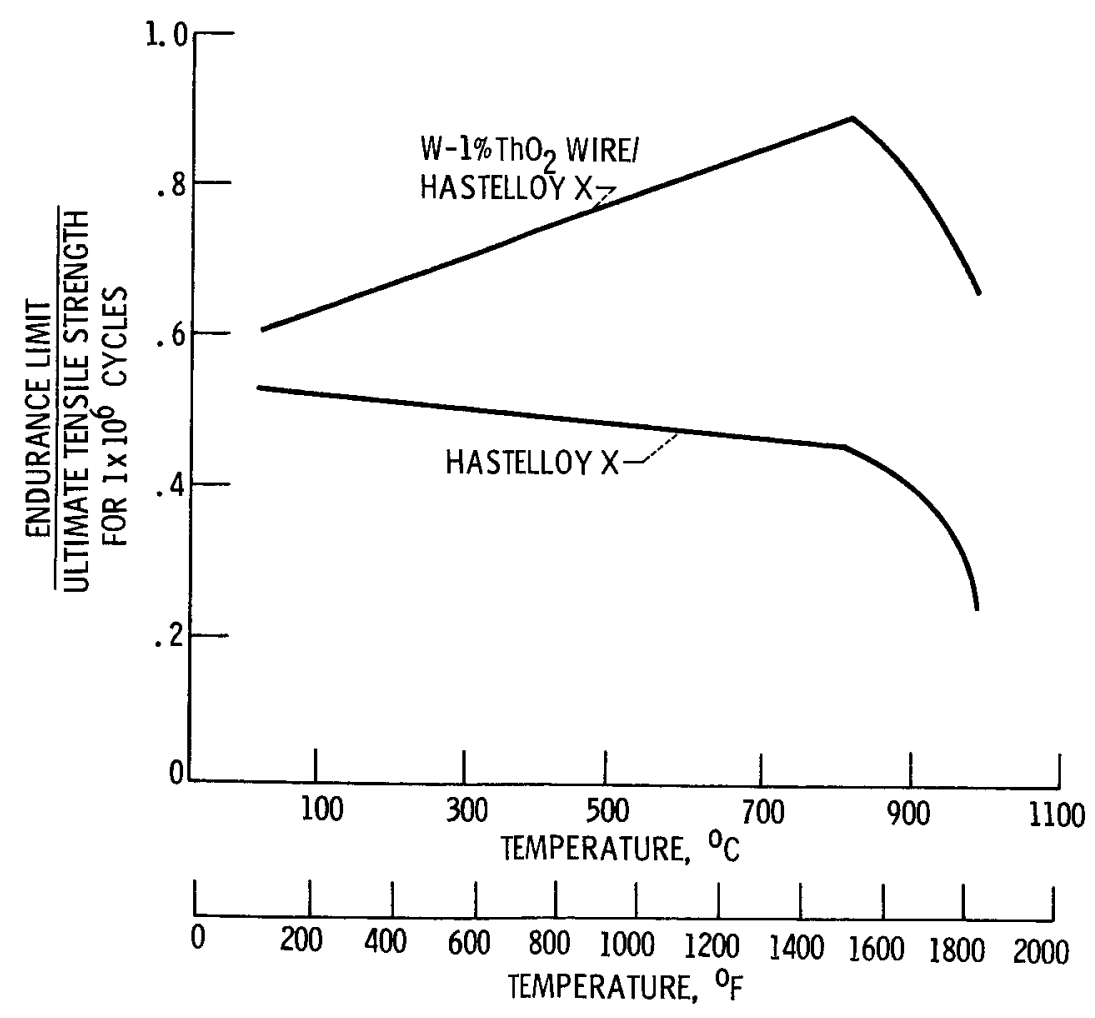

Figure 17. - Ratio of endurance limit to ultimate tensile strength for Hastelloy $X$ and composite tested in axial tension-tension. [6] 


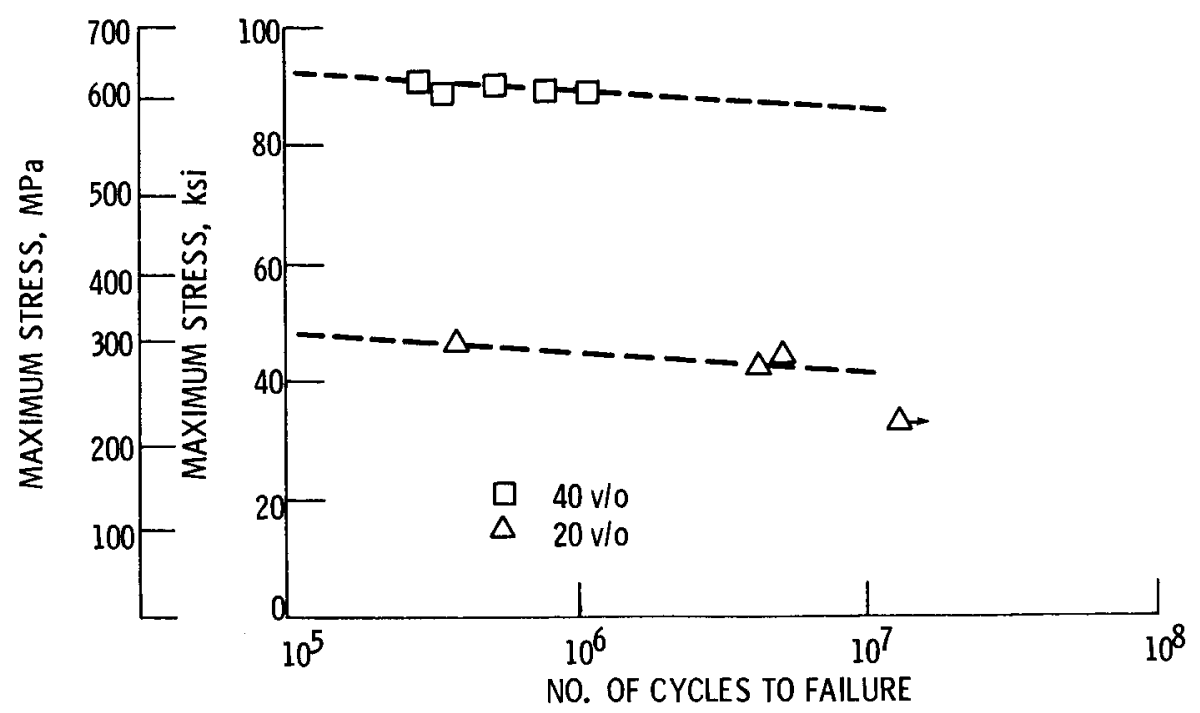

Figure 18. - Stress as a function of number of cycles to failure for $\mathrm{W}-1 \% \mathrm{ThO}_{2} I$ FeCralY composites tested at $760^{\circ} \mathrm{C}\left(1400^{\circ} \mathrm{F}\right)$. [19]

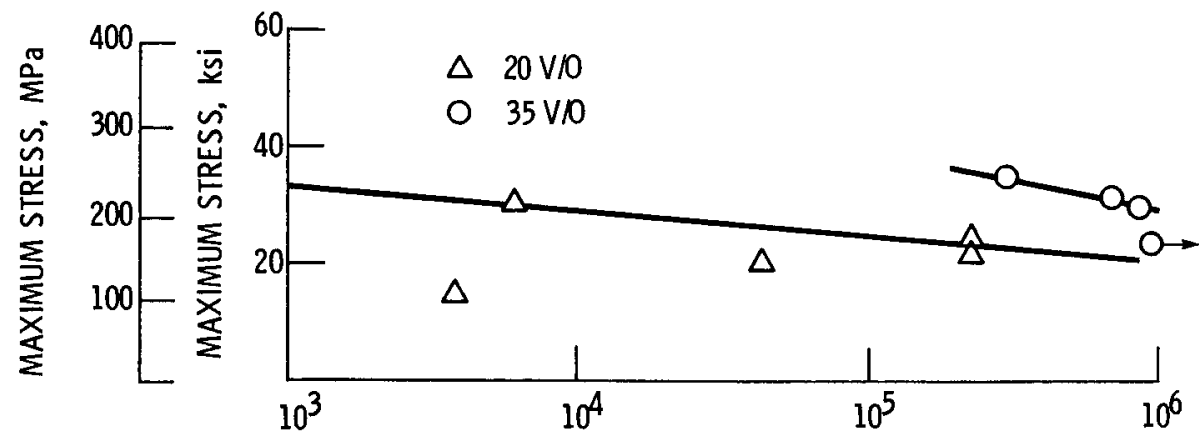

NO. CYCLES TO FAILURE

Figure 19. - Stress as a function of number of cycles to failure for $\mathrm{W}-1 \% \mathrm{ThO}_{2} /$ FeCralY composites tested at $1038^{\circ} \mathrm{C}\left(1900^{\circ} \mathrm{F}\right)$. [19]

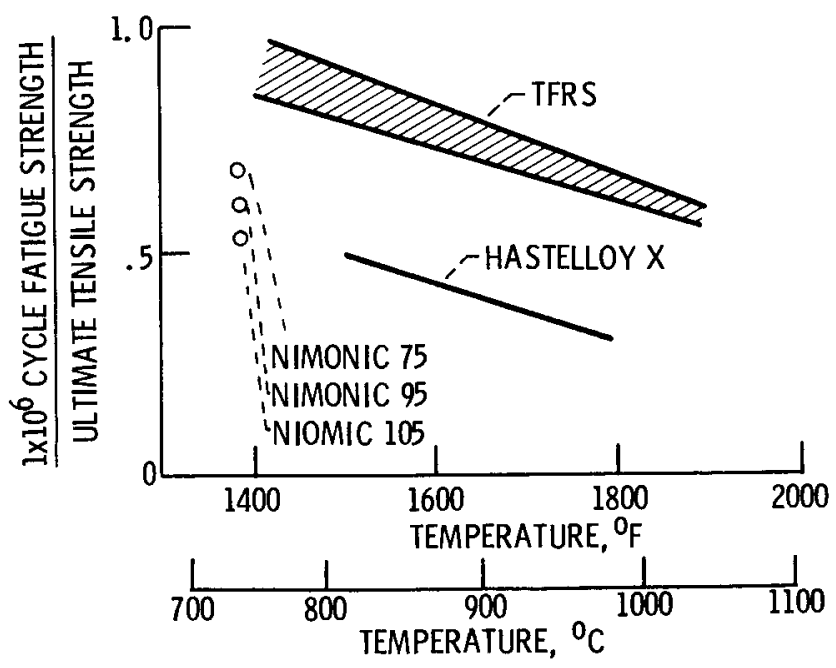

Figure 20. - High-cycle fatigue strength ratio comparison for TFRS and superalloys. 


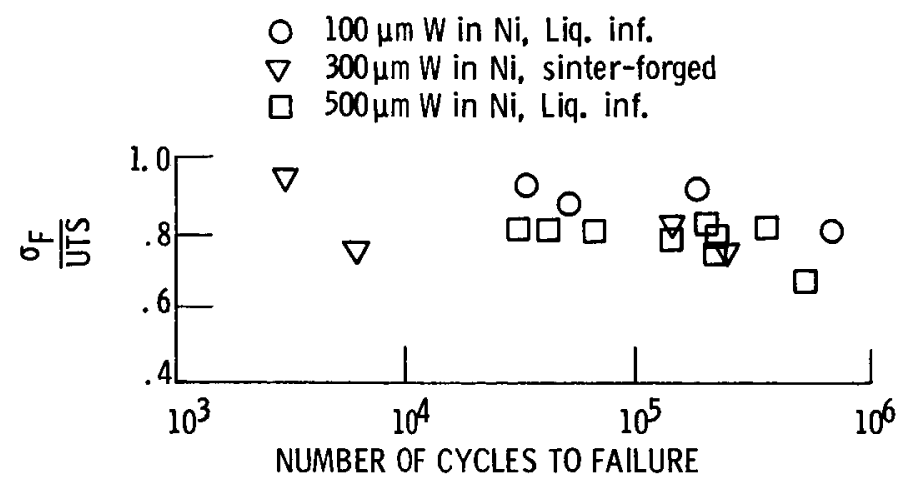

Figure 21. - Ratio of fatigue strength $\left(\sigma_{F}\right)$ to ultimate tensile strength (UTS) for Ni/W continuously reinforced composites. [40]

$\begin{array}{ccc} & \text { VOLUME, percent, FIBER } & \text { TEST TEMPERATURE } \\ 0 & 35 & 760^{\circ} \mathrm{C}\left(1400^{\circ} \mathrm{F}\right) \\ \square & 35 & 980^{\circ} \mathrm{C}\left(1800^{\circ} \mathrm{F}\right) \\ \Delta & 20 & 760^{\circ} \mathrm{C}\left(1400^{\circ} \mathrm{F}\right) \\ \Delta & 20 & 980^{\circ} \mathrm{C}\left(1800^{\circ} \mathrm{F}\right)\end{array}$

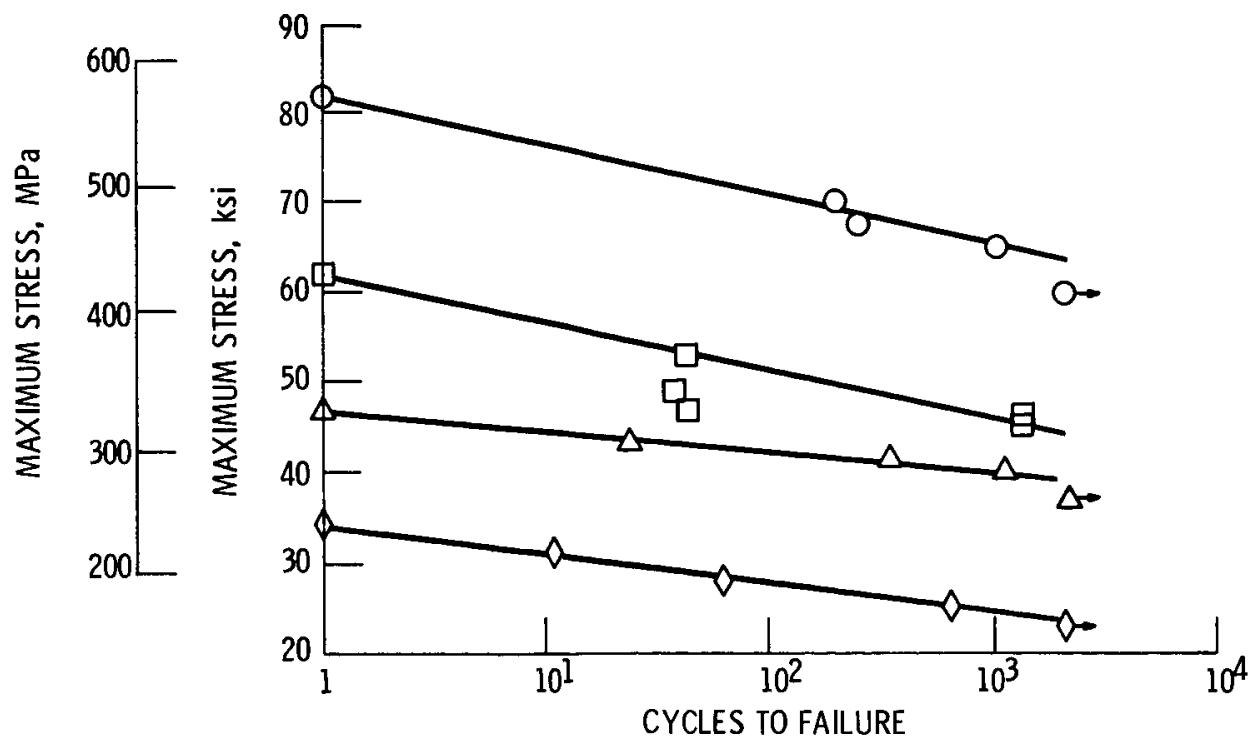

Figure 22. - Maximum stress versus cycles to failure for $\mathrm{W}-1 \% \mathrm{ThO}_{2} / \mathrm{FeCrAlY}$ composites. [19] 

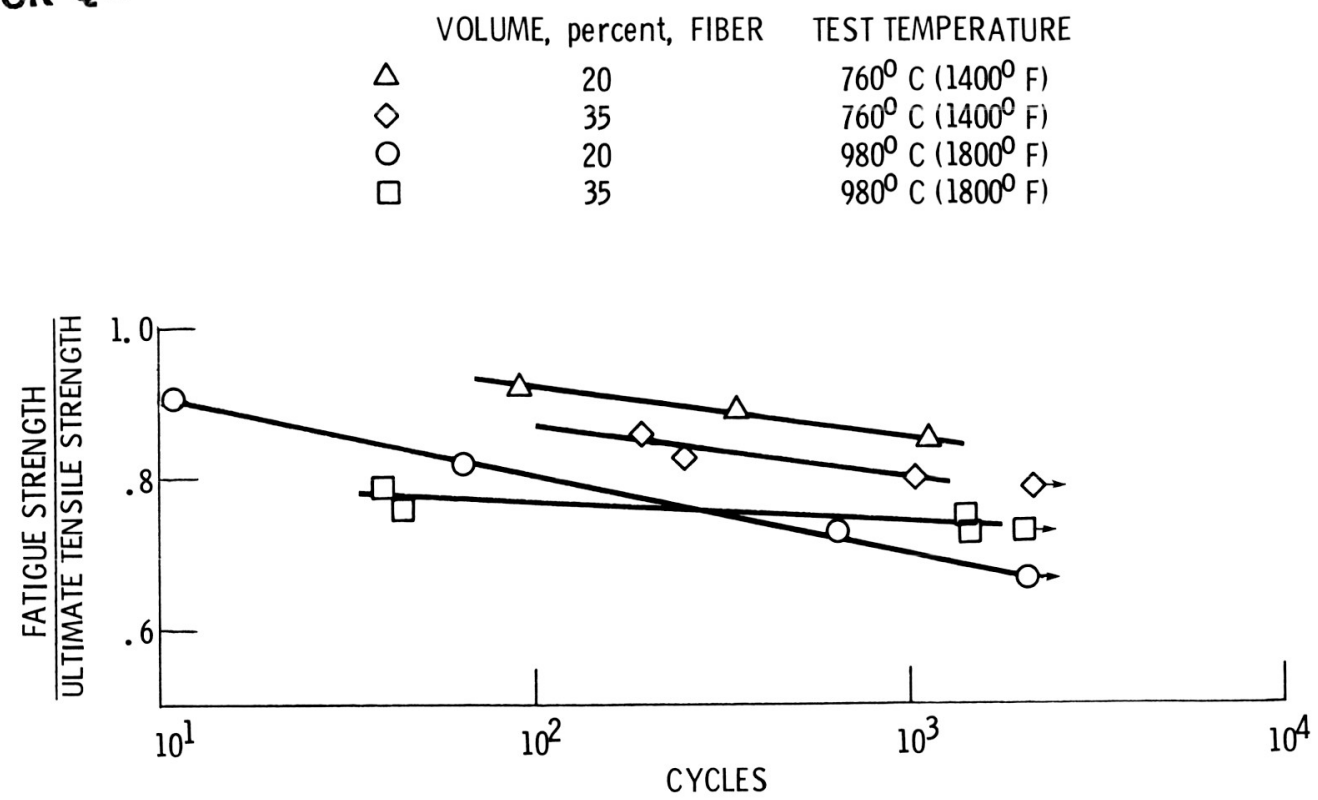

Figure 23. - Ratio of fatigue strength to ultimate tensile strength versus cycles to failure for $\mathrm{W}-1 \% \mathrm{ThO}_{2} /$ FecralY composites. [19]

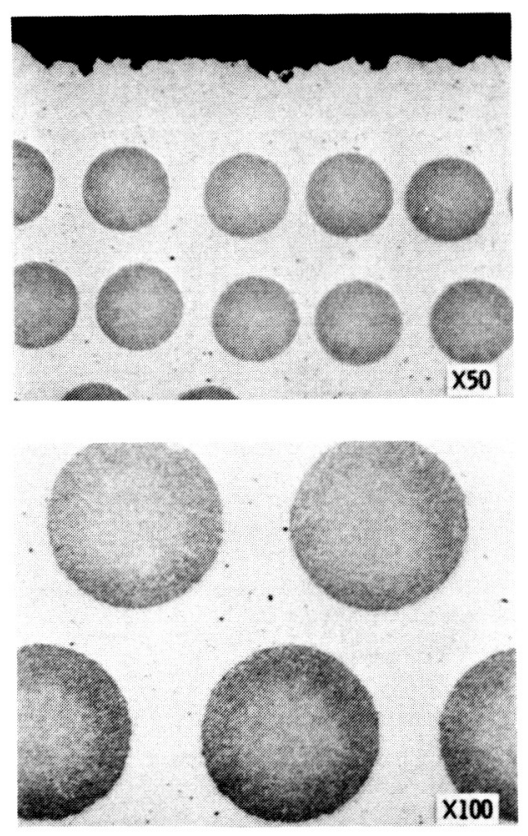

$1000 \mathrm{CYCLES} 30^{\circ}-1200^{\circ} \mathrm{C}\left(85^{\circ}-2200^{\circ} \mathrm{F}\right)$

Figure 24. - Photomicrographs of thermally cycled tungsten wire reinforced FeCrAlY composite. (Photos courtesy of Irving Machlin). [8] 

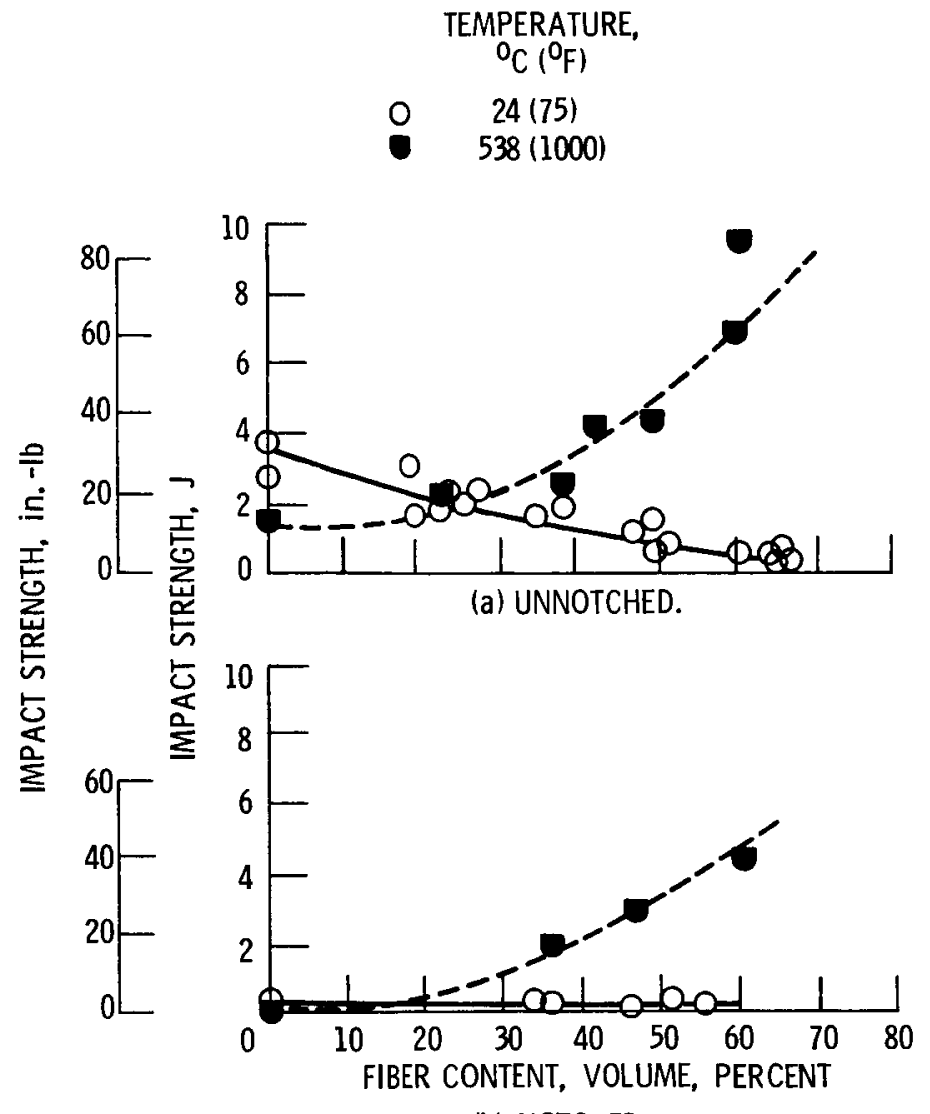

(b) NOTCHED

Figure 25. - Impact strength of unnotched and notched asHIP tungsten/superalloy as a function of fiber content. [57] 

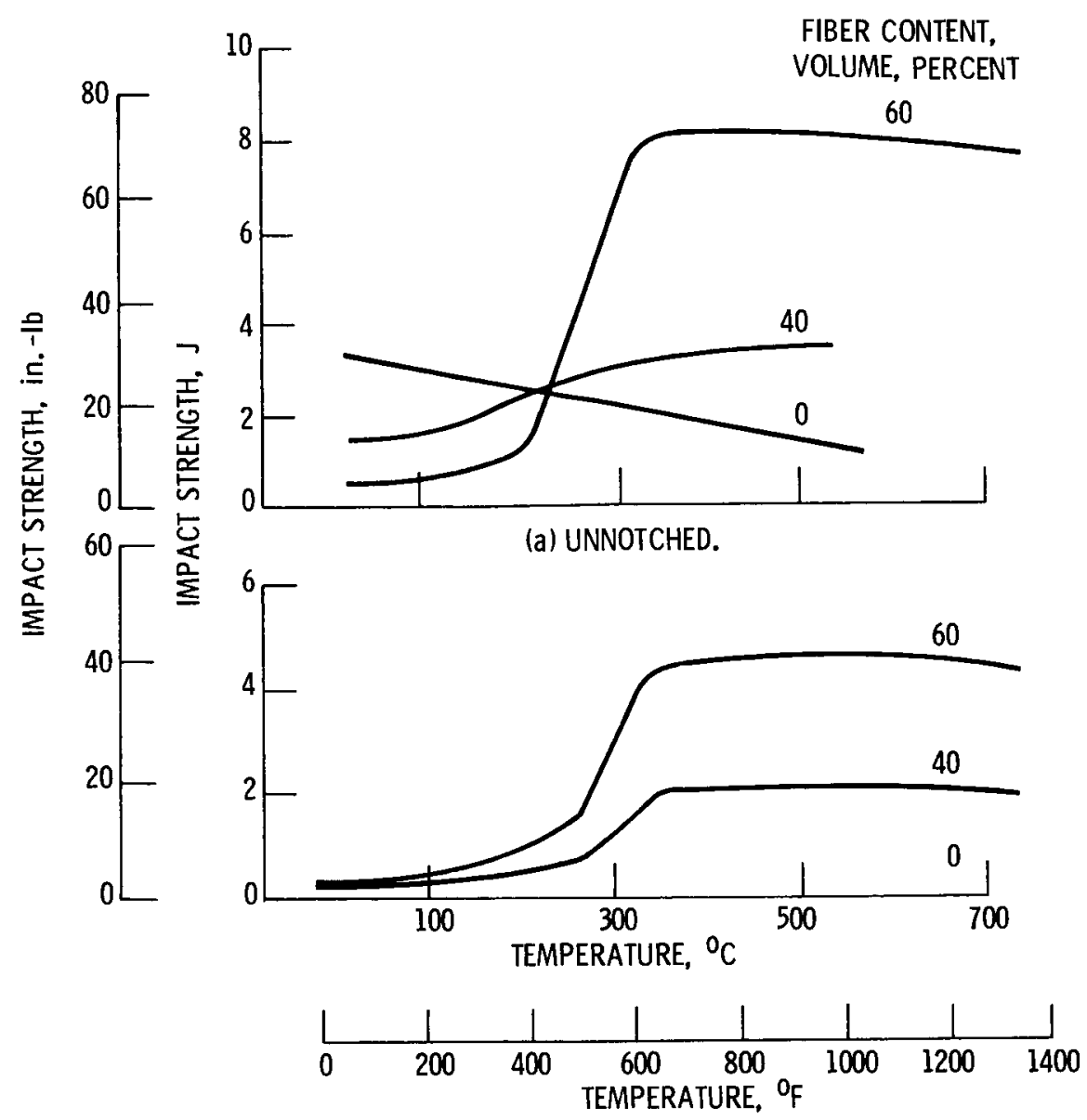

(b) NOTCHED.

Figure 26. - Impact strength of unnotched and notched tungsten/superalloy as function of temperature and various fiber contents. [57]

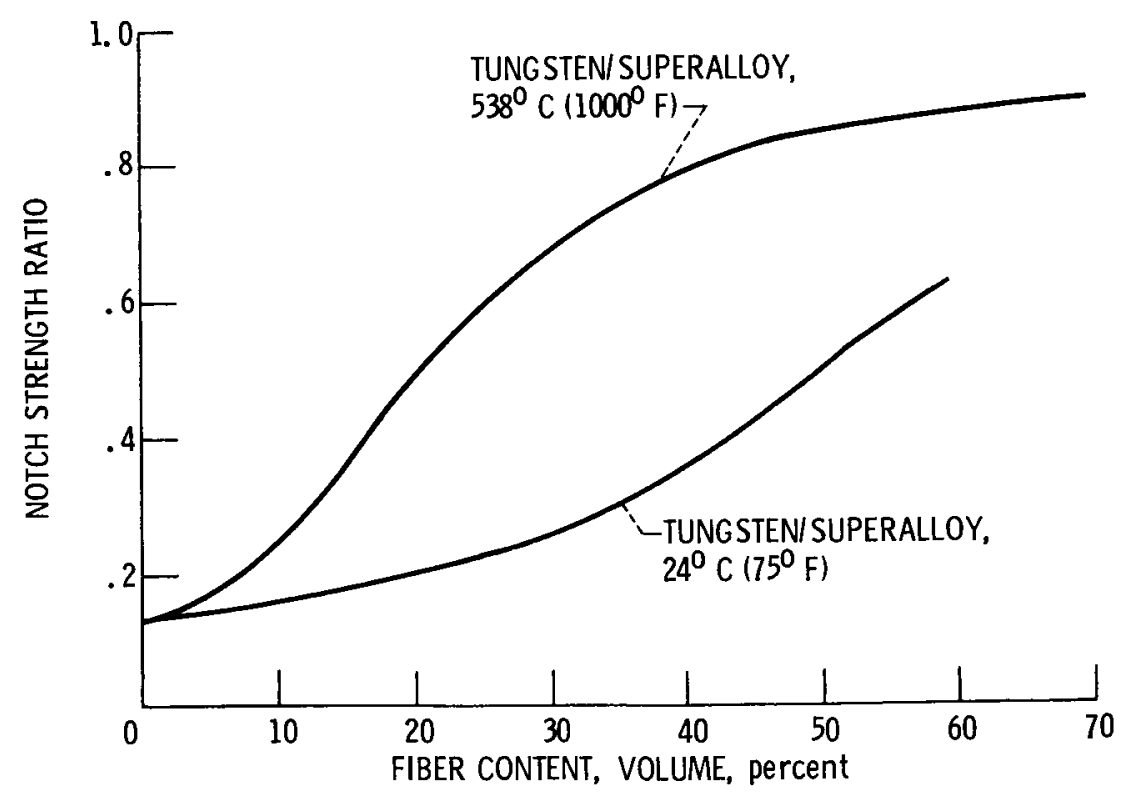

Figure 27. - Notch strength ratio as function of fiber content for tunqsten/ metal composites tested at 24 and $538^{\circ} \mathrm{C}\left(75^{\circ}\right.$ and $\left.1000^{\circ} \mathrm{F}\right)$. [57] 


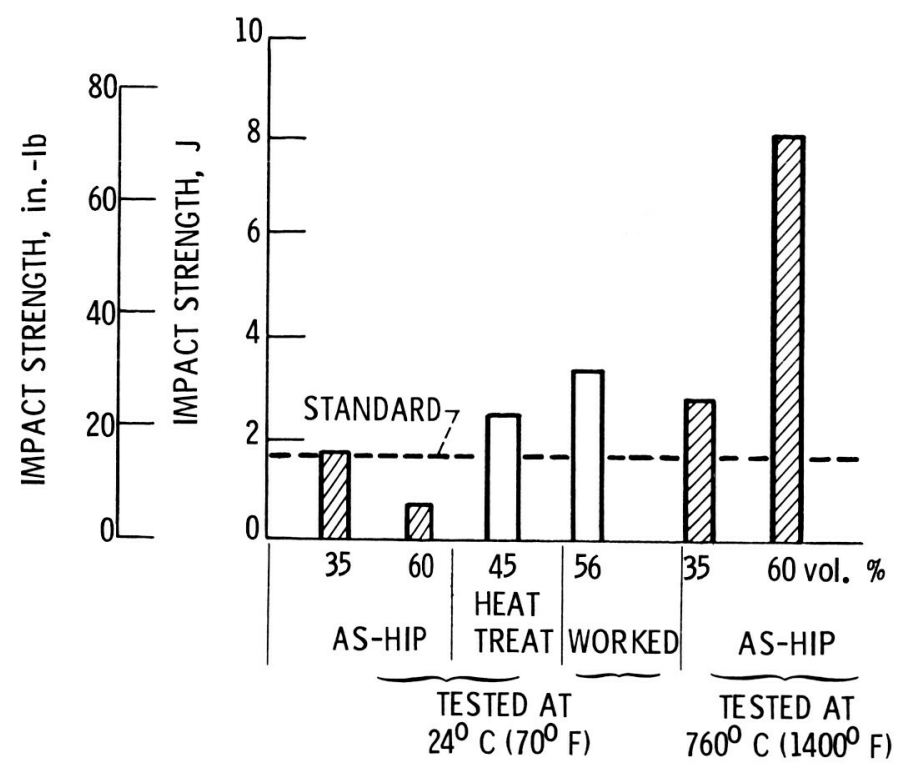

Figure 28. - Miniature Izod impact strengths of unnotched tungsten/nickel-base superalloys compared to minimum impact strength standard used to screen potential turbine blade and vane materials. [57]

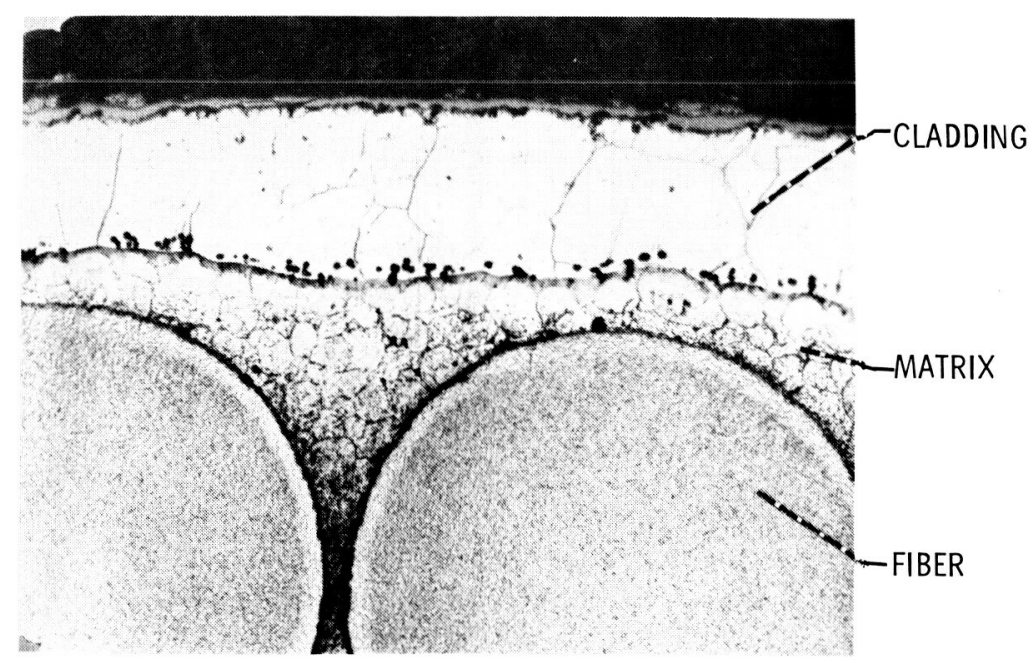

TEST CONDITION - EXPOSED TO AIR ATMOSPHERE FOR 50 HR AT $1093^{\circ} \mathrm{C}\left(2000^{\circ} \mathrm{F}\right)$

Figure 29. - Transverse section of oxidized refractory fiber nickel alloy composite. [44] 


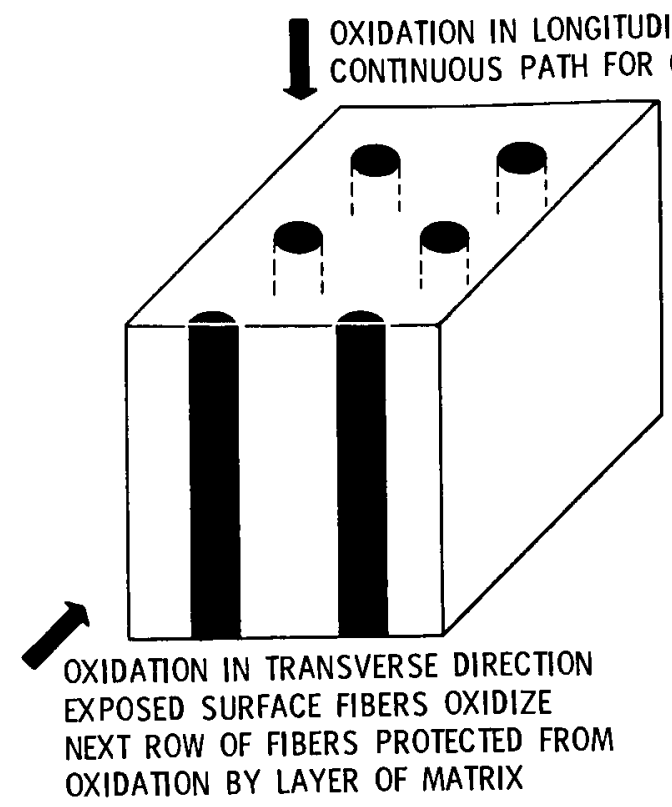

Figure 30. - Principal paths for exposed fiber oxidation.

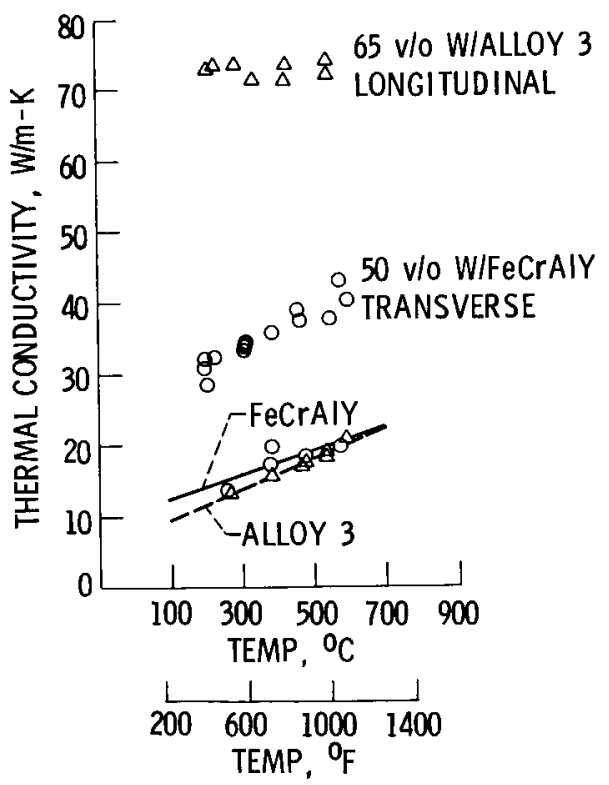

Figure 31. - Measured thermal conductivity of TFRS composites and matrix alloys. [58] 


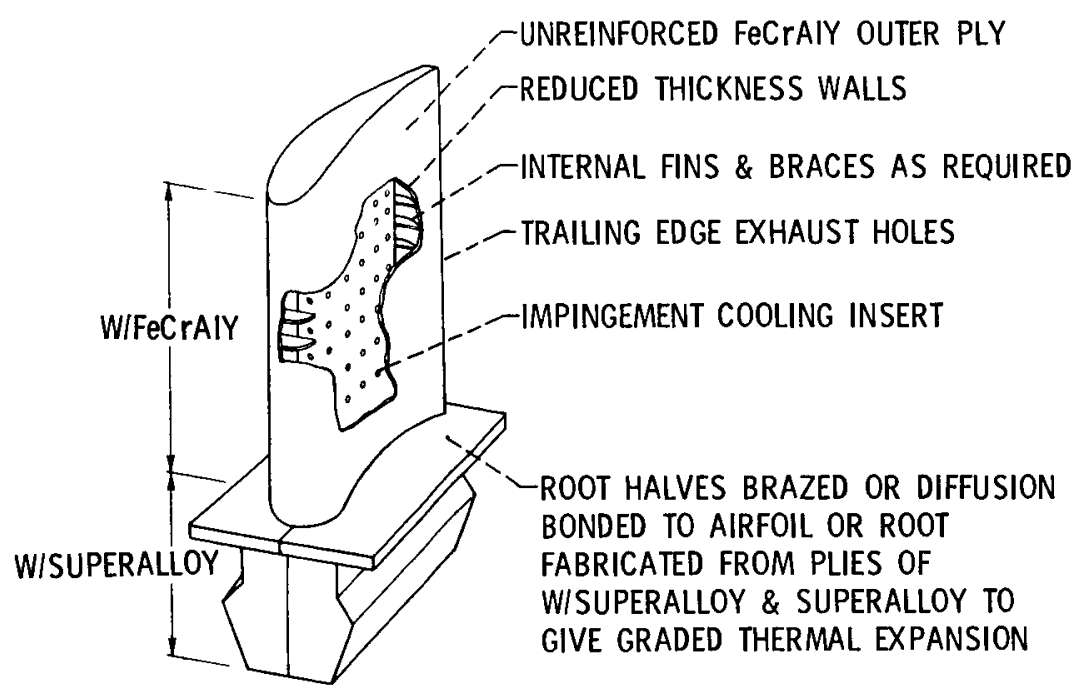

Figure 32. - Schematic of FRS JT9D blade designed for fabrication feasibility experiments.

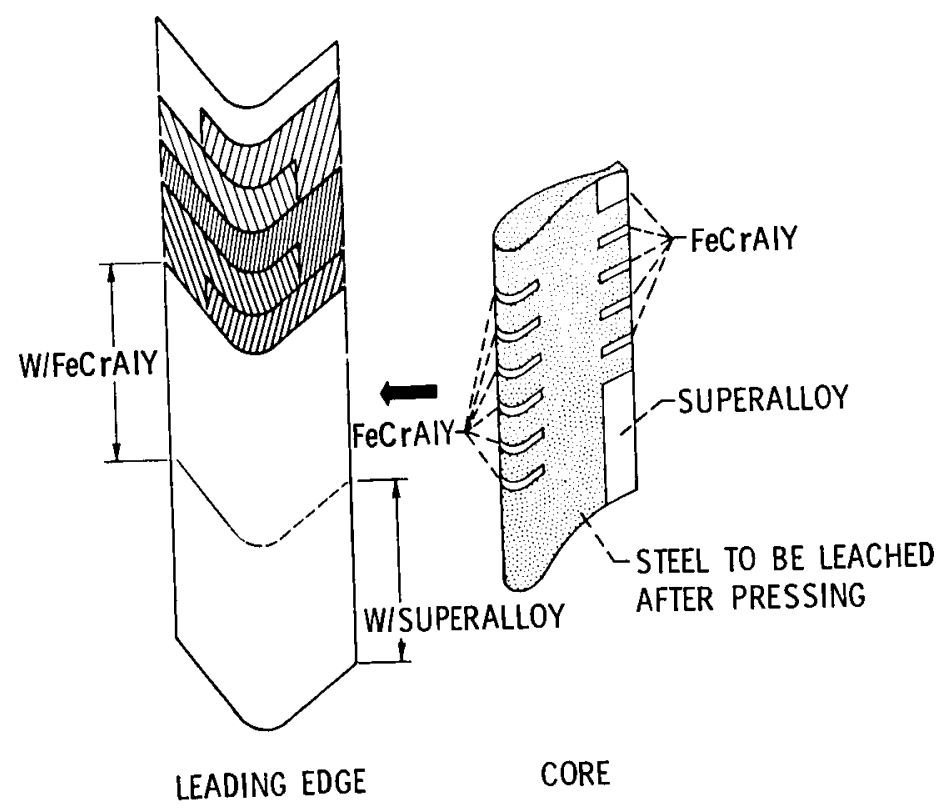

Figure 33. - Schematic of airfoil ply configuration in JT9D blade. 


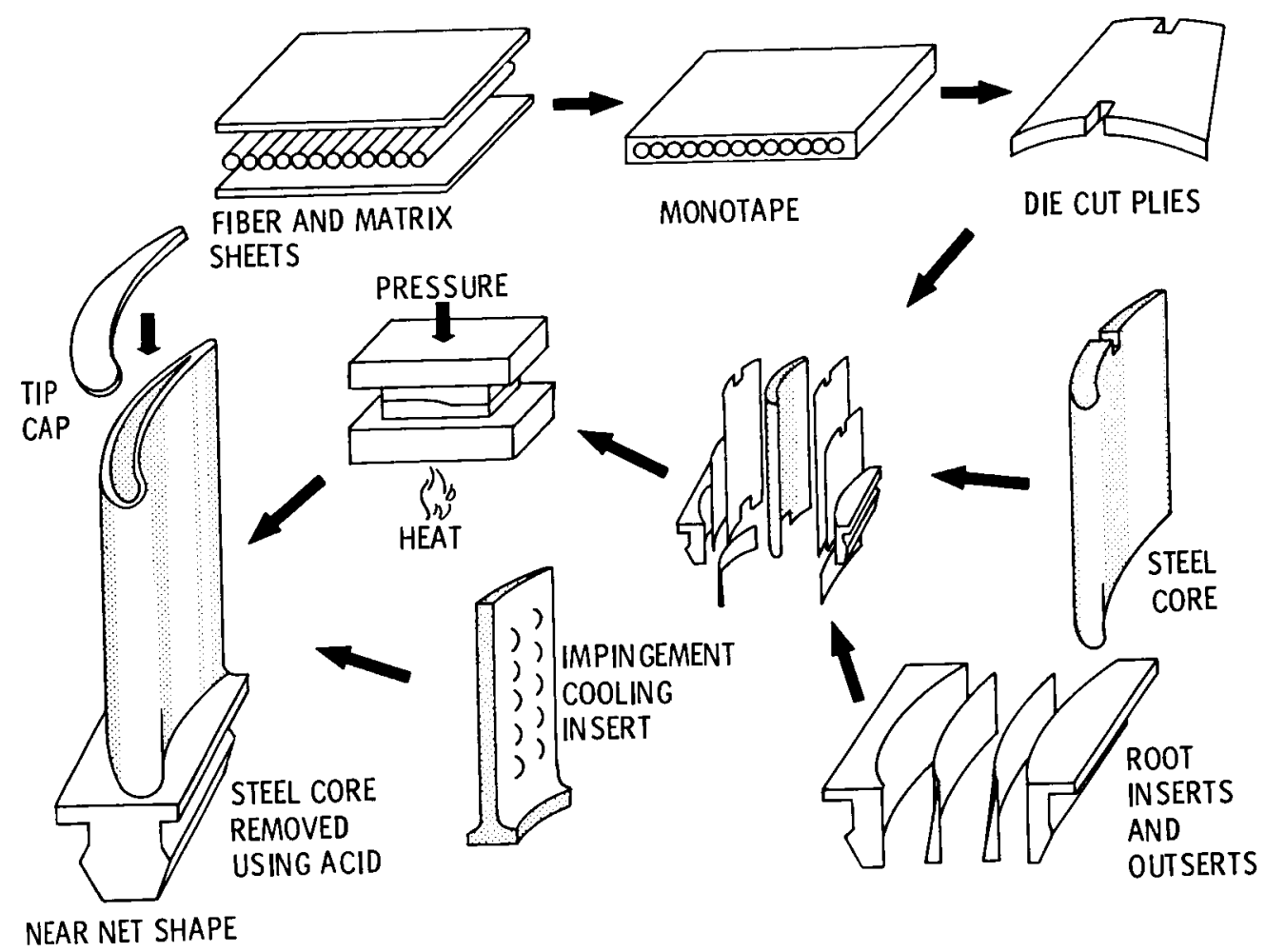

Figure 34. - TFRS blade fabrication process. 


\section{ORIGINAL PAGE IS OF POOR QUALITY}

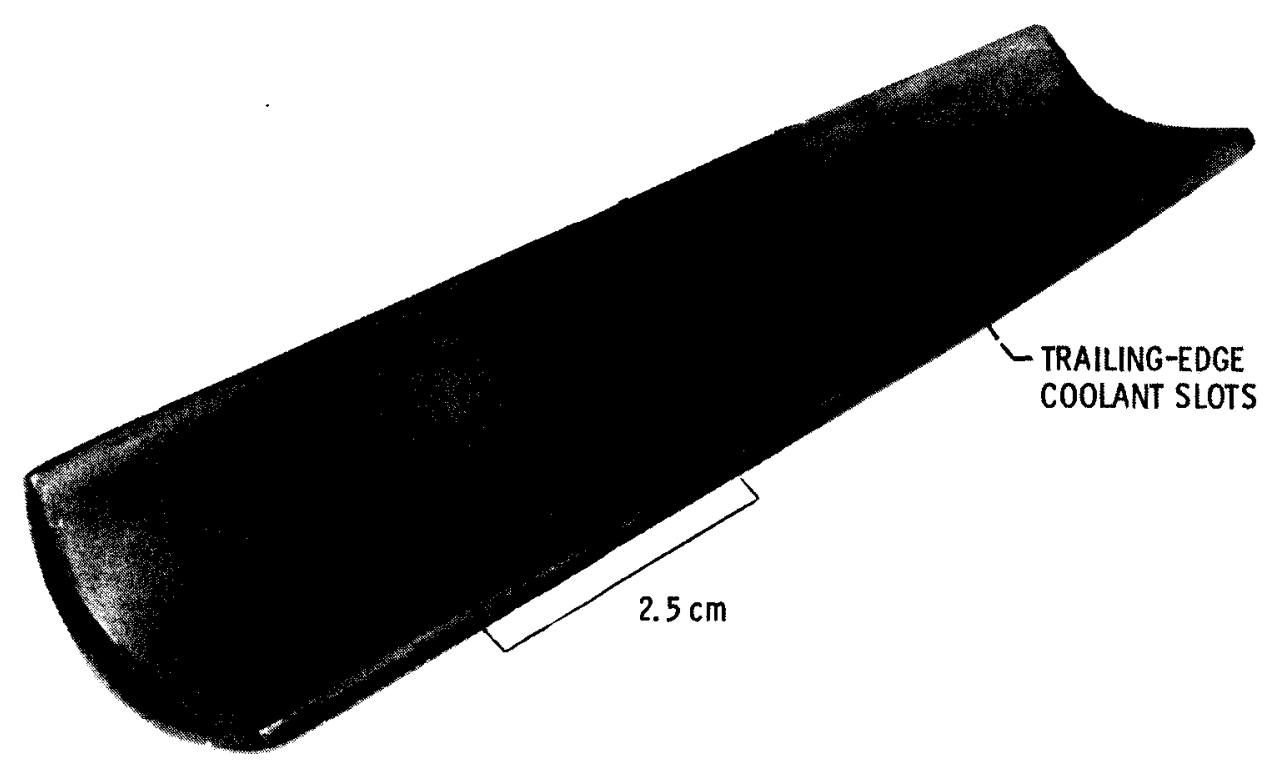

Figure 35. - Composiie hollow airfoil.

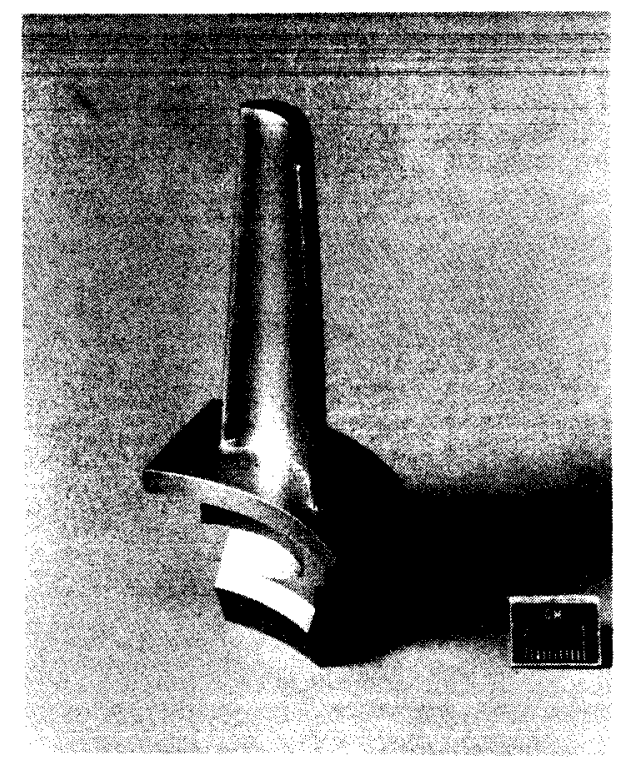

Figure 36. - Hollow composite blade. 


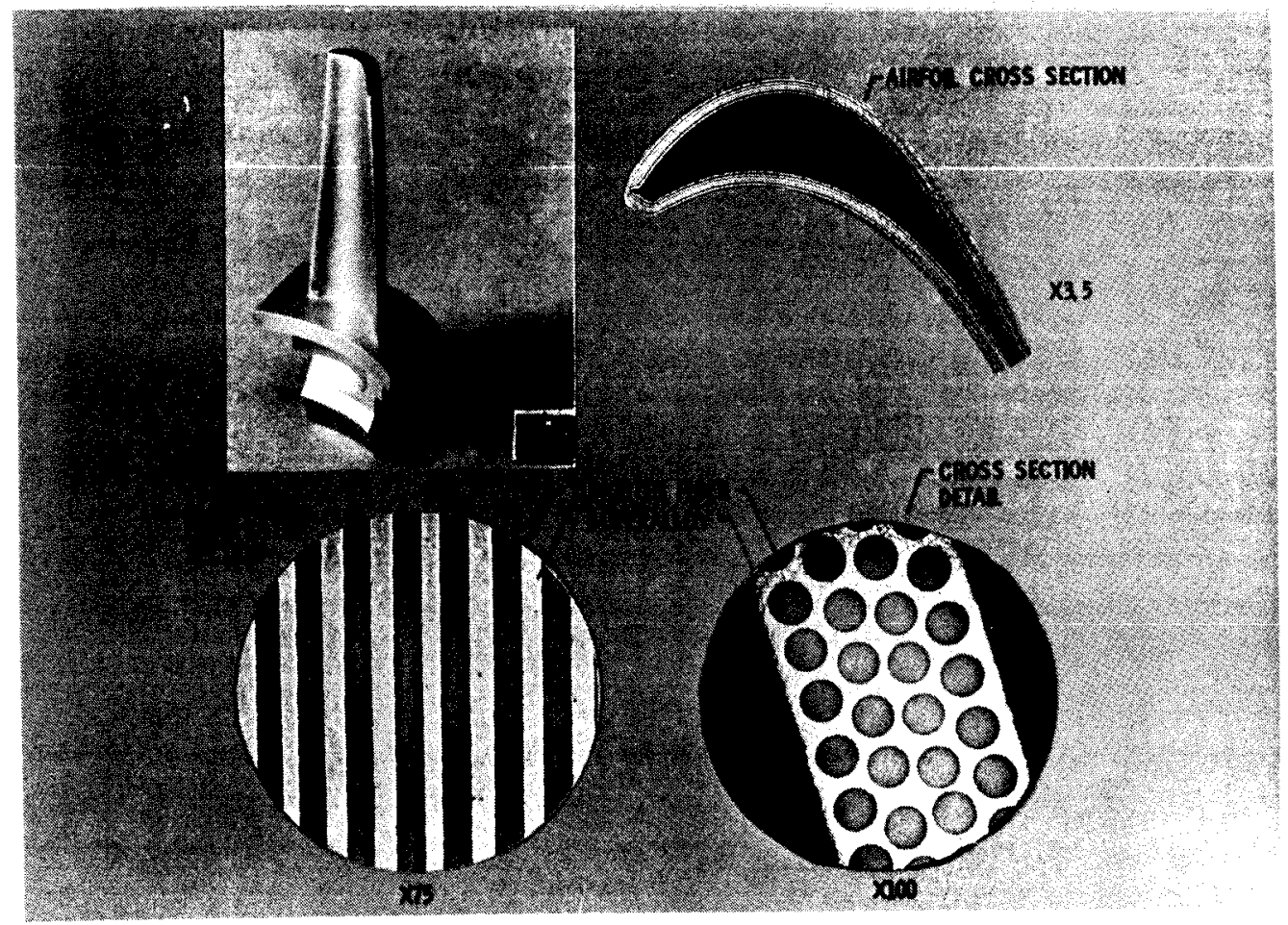

Figure 37. - Tungsten fiber/superalloy composite blade.

\section{ORIGINAL PS.GE IS OF. POOR QUALITY}

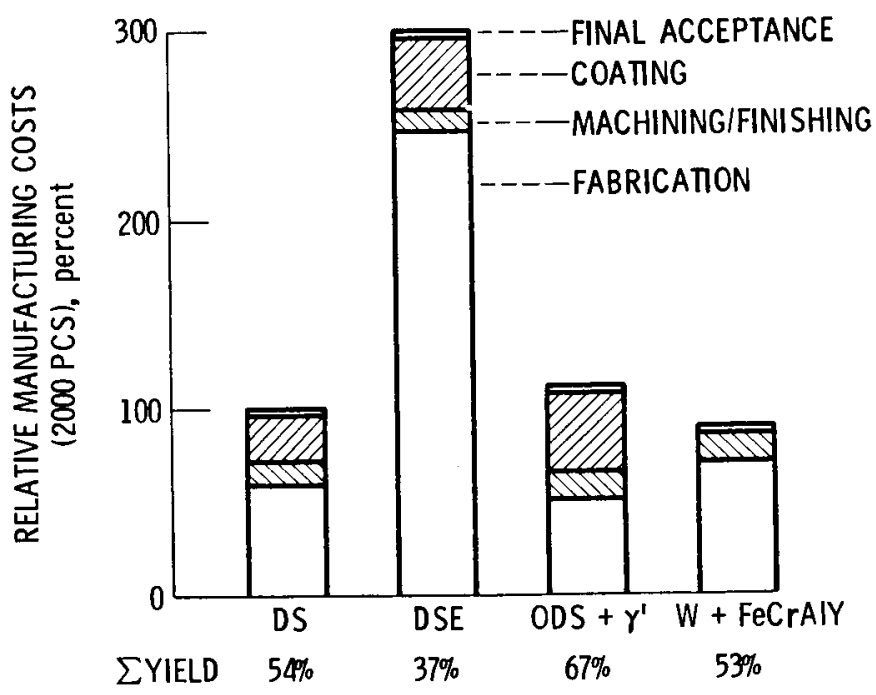

Figure 38. - Cost analysis for JT9D first stage turbine blade. [5] 


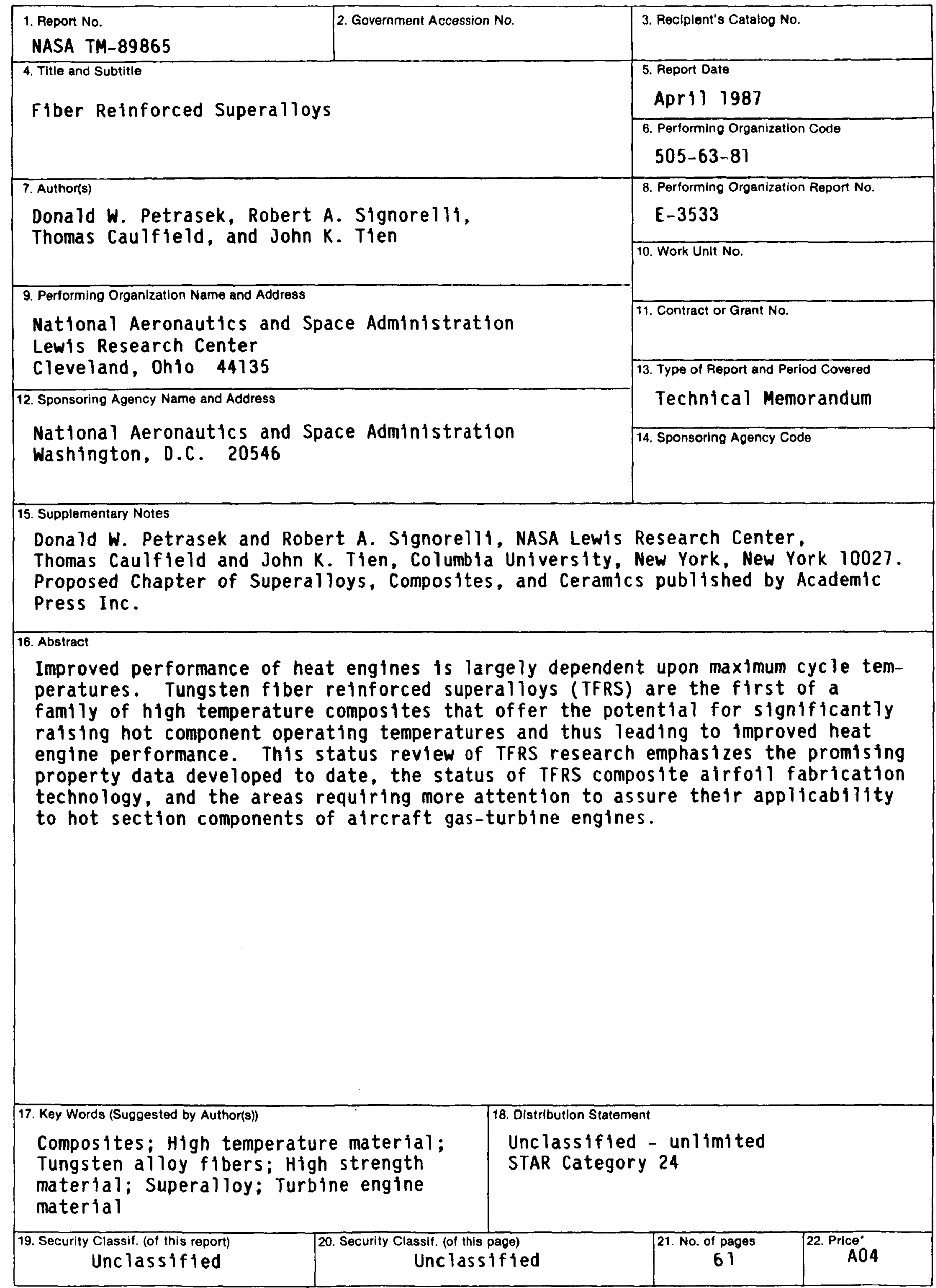

*For sale by the National Technical Information Service, Springfield, Virginia 22161 